\title{
Mural as public art in urban fabric: An attempt to link configurational approach to perceptual morphology
}

\author{
Cansu Demir Türközü* \\ Olgu Çalışkan** (D)
}

\begin{abstract}
The intrinsic relationship between art and the public has changed as public art has greater visibility in contemporary urban space. Especially following the growing interest in placemaking in spatial planning and design, many cities in different countries tend to experience an unprecedented transformation of urban space displaying various modes of artistic performances open for the public. As a visual art, the mural could be considered one of the leading creative activities in the cities' public domain. The ever-increasing popularity of murals as public artwork made the local governments tend to introduce some programs to steer the performance of the art within the very spatial condition of the city fabric. Along with its vivid cosmopolitan culture, Istanbul has performed as the cultural hub of the contemporary arts located both indoor (the various size of galleries) and the city's outdoor spaces. As one of the central neighborhoods in Kadıköy district in İstanbul, Yeldeğirmeni, represents a very relevant context to investigate the issue public art in urban space. Having accommodated an international mural festival in 2012, the district has turned into an experimental site for various mural practices. The extent of the art in the urban space calls for morphological research to test the perceptual performance of the artwork in terms of the characteristics of the physical fabric in which the murals locate. The paper, in this context, conducts a spatial analysis focusing on network integration, visibility, and townscape characteristics of the neighborhood fabric. The research findings are correlated with the level of recognition of the murals by the public to reveal the conditional relationship between the spatial morphology and the perceptional capacity of the murals as public art.
\end{abstract}

Keywords: public art, mural, perception, urban morphology, townscape

\section{Introduction}

The ways of reproduction of social life, which has been culturally transformed in urban societies, parallel the subtle transformation of the public space. With the advancement of social communication networks through intensive digitalization, human experience in physical urban space (i.e., activity, mobility, and perception) tends to change radically. Inclusivity of the public sphere is the historical character that has been formed and evolved by the mutual interaction of the free individuals (Habermas, 1997); therefore, it is characterized by the politics of democratic accessibility to the public space mainly through 'social expression' of the body (Negt and Kluge, 
1993). Since the Ancient Greek period, when the definition of the citizen was rather exclusionary (for women and slaves), the modern understanding of the public sphere has evolved through the multiple and pluralistic notion of the socio-space through different forms and practices (Arendt, 1958). At this point, art as one of the most vital expressions of human imagination and mind in the public domain represents a critical position for the future transformation of the democratic public space.

From that perspective, supporting the artistic creativity of the individuals and the right to selfexpression has turned out to be critical strategies for the current urban policies aiming for sustainable transformation of public spaces in the cities (Landry, 2020; Hall and Robertson, 2001). In the recreational spaces and various programmatic spaces (i.e., educational, medical), urbanites of different ages are encouraged to experience the art and the artistic performance (Remesar 2005; Lovell, 2020). With its unique character, even a temporary artwork installed in a public space can positively impact the collective memories within common spaces of everyday life. Reshaping our imagination, public art is considered a kind of social practice that conditions the spatial memory of the city (Lovell, 2020). The public art forms which have a relatively shorter lifespan, such as graffiti and mural, mostly have no existence other than the memories of those who encounter and experience them in space (Erdoğan, 2014). Considering the conditional relationship between the patterns of perception and experience and urban space (Bosselmann, 1998), one could argue the critical role of urban design in the perceptional quality of the public works of art. As Phillips (1988) discussed, the publicness of art in space is highly dependent on the capacity of the artwork to be accessible by the public (Phillips, 1988: 97 cited in Ercan, 2013: 226). Therefore, it is necessary to carefully establish an effective relationship between the artwork and the urban space for better communication between the arts and the people. The desired accessibility condition, in this regard, could be set both visual and physical manner.

In that framework, following a brief discussion on public art and the city, the paper will problematize murals in the urban fabric regarding the issues of perception, morphological and townscape characteristics of urban form and structure. Recognition of the mural in the urban fabric as the perceptual performance of the public art is discussed via a set of spatial analyses conducted on the actual case of Yeldeğirmeni Neighborhood, Istanbul, Turkey. As one of the experimental areas of public art since the Mural Festival in 2012, the neighborhood suggests a relevant spatial setting to discuss the issue on a morphological basis. In the specified context, aiming to delineate the key spatial factors that influence the level of visual recognition of public art in a dense urban fabric, the research, initially, utilizes the configurational analyses of Space Syntax and Isovist. While the former set of analyses measures the physical accessibility of the murals, the latter considers visual accessibility as the fundamental condition of the perceivable presence of the artwork in space. Then investigating the perceptional capacity of urban space regarding public art will be elaborated with the townscape analysis. Here, the basic argument of the paper is that high public recognition of the artworks in space could be ensured not only by the spatial and visible accessibility but also through some supporting townscape characteristics of the built environment.

Developing some 'complementary models' combining the different methodological approaches represents one of the most up-to-date research questions in the field of urban morphology. The recent attempts to suggest a composite view on alternative methods, in this regard, tend to suggest the integrated model frameworks relating the configurational approach (of Space Syntax, in most cases) to the historico-geographical school of morphology (Griffiths et al., 2010; Li and Zhang, 2020; Allahmoradi and Cömert, 2021), spatial analytical approach (Oliveira and Medeiros, 2015) or all the others -historico-geographical, typological, and spatial analytical- (Oliveira et al., 2014; Monteiro and Pinho, 2021). Within this context, the configurational approach has yet to be integrated with the perceptional dimension of urban form, in other words, the so-called 'perceptual morphology' initially delineated by the conceptual and analytical framework by Cullen (1961). 


\section{Public art and the city}

In every period of history, the common space has reproduced itself with the representational power of public art, commonly as the symbolic expression of the political power of the authority. Since the ancient periods, monumental works have been installed in the city's sacred and symbolically representational spaces (Januchta- Szostak, 2010). Positioned as a powerful tool in constructing a shared identity, public art has been frequently used by the political authority in principal spaces during the periods when social life and political structure underwent some ideological transformations. For instance, with the proclamation of the Republic of Turkey, the new public spaces of the modern regime were created by the state along with the aestheticization of the new national identity and the powerful image of its founder (Yaman, 2011), (Figure 1).
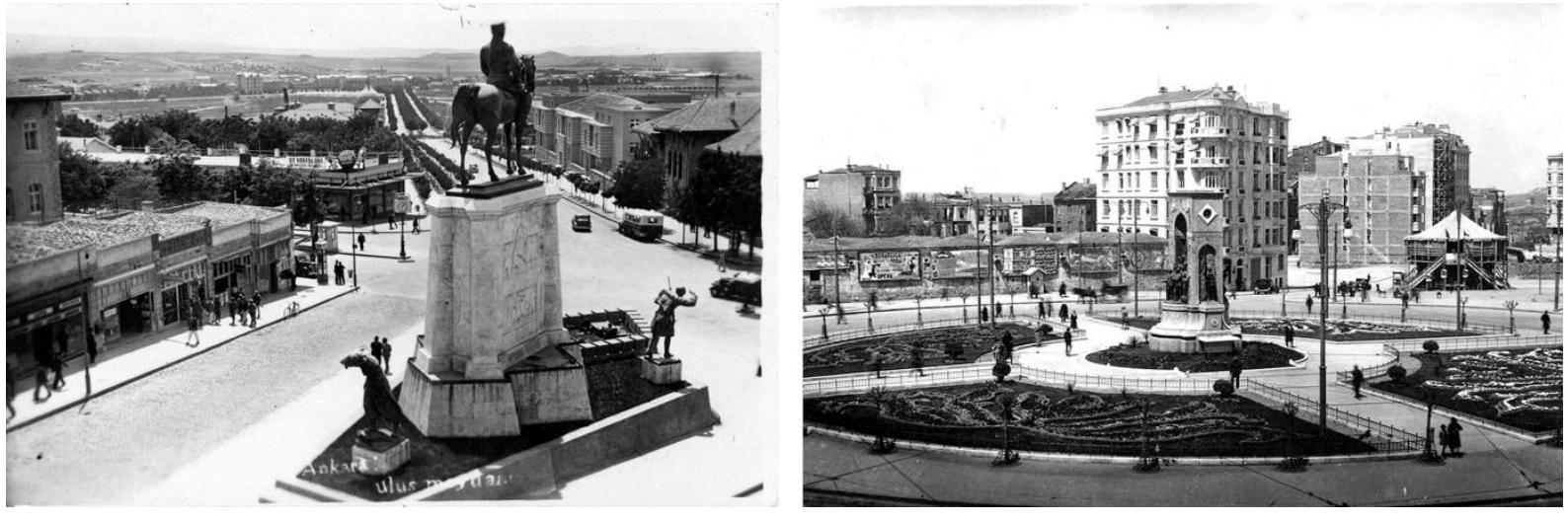

Figure 1 Monuments marking the public space of modern Turkey: public art to aestheticize the national identity in the making (Source: URL-1, URL-2).

In that view, one could consider the monumental works of art contributing to the construction of national pride and secular citizenship in the early republican period, the first systematic approach to public art in urban space in Turkey. These monuments making a historical contact with the present by representing the past establish a sort of temporal linkage with the space (Miles, 1997: 37). That implies the ideological reproduction of the state power via public artworks.

Following the development of the art industry as privately sponsored curatorship and collection programs, the critical movement against the production of the so-called 'high-art was to emerge in Europe and the States in the 1960s. Accordingly, the critical interpretation of public art was manifested as a radical discourse of the avant-garde movement that claimed public space as an alternative to the institutional reproduction of the art within galleries having limited accessibility by the public (Januchta-Szostak, 2010). The artist, within that view, is envisioned as the one putting their artistic performance, not in the art studio but urban space (or nature) by using alternative materials (i.e., waste), emphasizing some socio-political issues such as ecology and modern industrial society (Lacy, 1995). Thus, the dominant domain of public art would be more public, and respectively, political. The artists who question the fashion of performing the art through exhibitions, galleries, and museums believed that publicity would provide free expression with its social or political meanings, which cannot be revealed simply by the notion of open access (Hein, 1996). In this regard, the perception of art was to transform from a kind of individual practice that revolved within the specialized institutional bodies to something more integrated into daily life through the subtle transformation of society (Kortbek, 2018). The conception of art as the medium of social expression gave way to the 'New Genre Public Art' performing outside the institutional frameworks by calling artists for direct engagement with the audience while addressing sociopolitics (Lacy, 1995). All those might suggest that behind the prevalence of modern art in the public space, a particular political motivation tends to make the artistic experience, somehow, a part of the people's practice of every life. 
Murals, in this context, could be considered one of the powerful representation techniques regarding the accessibility of a politically symbolic or pure abstract expression of the artist to the public. One of the most striking examples of the new genre of public art is 'Mexican muralism.' Having started in the 1920s, just after the Mexican Revolution, the promoted act of mural painting conveyed the 'visible' message of the nationalist and socialist ideology on public buildings. As a kind of artistic movement, Mexican muralism strengthened the relationship between society and revolution while the artists had an extensive chance to express themselves in the public domain (Baca, 2013).

As argued by (Phillips, 1988), the idea of 'public' has a volatile and somewhat blurred conceptual ground since it has a psychological construct (pp. 93). Therefore, the common consent of the public on the aesthetics of the work of art in the public domain, in some contexts, emerges as a conflicting issue. For instance, Richard Serra's Tilted Arc sculpture placed in Foley Federal Plaza in Manhattan, NY, in 1981 was not accepted by the public who were using the place. Then, it was removed by the court decision (Miles, 1997). Likewise, John Ahearn's sculptures in South Bronx, NY represented the common profile of the neighborhood's social structure and stories. They could only remain for five days on the pedestals in public space following the protests by some residents who found what was represented by the artist inappropriate (Kwon, 1997). In this regard, the visibility of the public artwork in urban space turns out to be a critical factor for the performance of the art in the public domain regarding the profile of the people that the artwork aims to communicate.

Similarly, along with the so-called counter-cultural hegemony that the political authority tends to establish for the last twenty years, the issue of public art in space has been subject to discussion within many cities in Turkey. The mainstream populist tendencies in central and local governments have resulted in a series of implementations of the artworks in public space, mainly in the form of sculptures as the pure representation of local identity and cultural figures without any abstract quality involved. The current political authority, in this sense, performs in subtle reaction against the abstract representation of modern art to be visible in the public space in Turkey. Having started with harsh criticism against a sculpture, which the previous social-democrat municipality had installed, as one of the examples of abstract art (Figure 2, left), the 'counter-anesthetization' of the populist government goes on with various applications engaged with the ideological symbolism of the ruling ideology in a very figurative style (Figure 2, right).
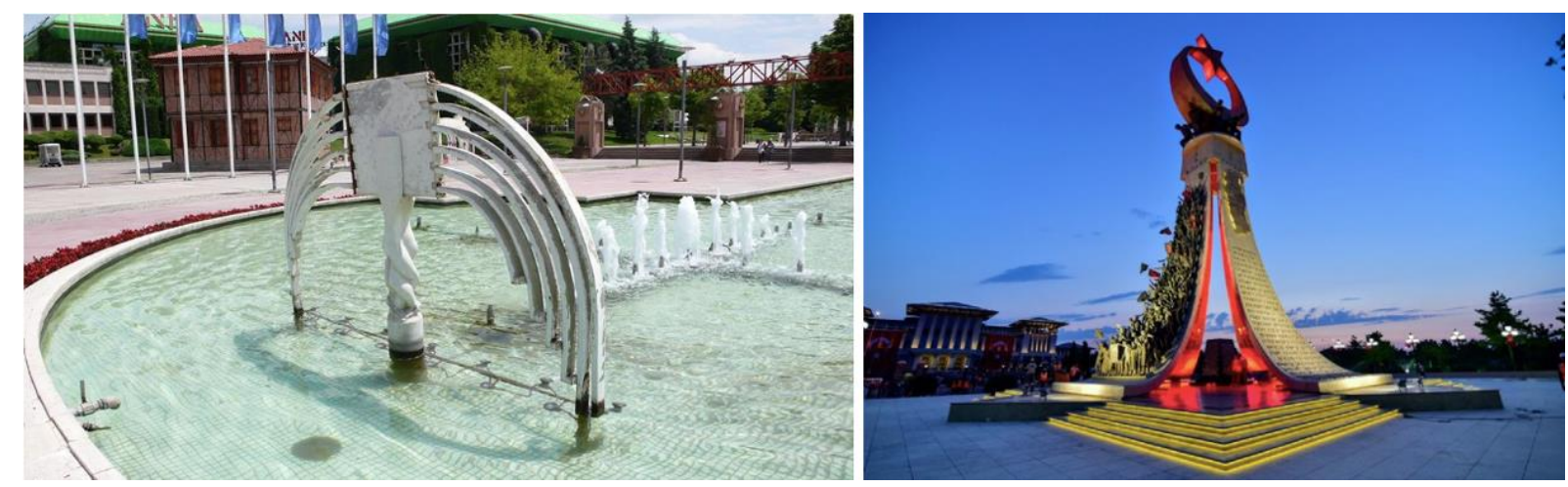

Figure 2 Sculpture as the prevalent type of public art in Turkey: the abstract versus figurative representation as a tool for cultural politics reflected on space. (Source: URL-4, URL-5) 
Nevertheless, especially in the metropolitan cities in Turkey, there has been a solid tendency to integrate art into the public space initiated by civil society and the new local governments aiming to revitalize the public space and create a vibrant image of public life in space. In this regard, it is possible to observe many programs and organizations which systematically involve the art and artistic performances in public space as a tool for community development and placemaking (Figure 3).
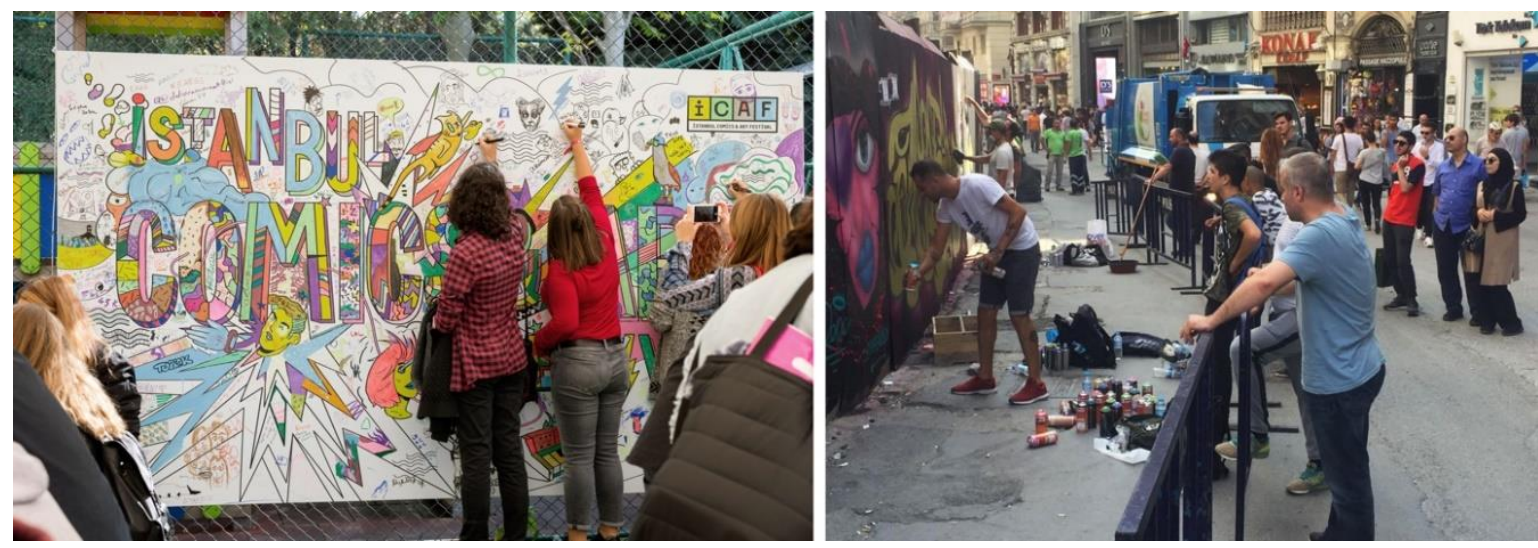

Figure 3 Istanbul Comics \& Art Festival provided some experimentation platforms (i.e., outdoor workshops and exhibitions) in public space (left), and the graffiti artists drawing under the gaze of people on the street (Source: URL-6; personal archive, 2017).

In this context, it is quite possible to argue a subtle transformation in the common perception of public art in Turkey. While it used to be dominantly performed with the initiative of central governmental authority before, the public art in Turkey is in the way of the self-performance of the art by the society in close relation to the local governments. Such emerging dynamism essentially acts as a factor that tends to socialize public art phenomena collaboratively. In this sense, the increasing number of experiments in various public spaces and living environments in Turkey make us revisit the issue from a social and spatial perspective as an alternative to politics.

As commonly accepted in the literature, integrated with the environment, public art plays an essential role in strengthening local identity by creating a sense of place with all the other spatial properties of a given context (Selwood, 1994; McCharty, 2006). Art potentially transmits the local histories and unknown stories of the space and presents a collective image to the society (Porch, 2000; Kwon, 2002; McCarthy, 2006). Moreover, it has an intrinsic power to support cultural diversity through encouraging the integration of marginalized groups into the larger society by including them in the processes of cultural representation (Hall and Smith, 2005: 176). In the contexts where it has a solid social basis, public art could be considered a means of reproducing society within the domain of the cultural public (Selwood, 1994). The emotions aroused by the art in the public domain revive awareness and relate people to the space (Hall and Robertson, 2001), transforming the space into a meaningful environment.

In terms of the collective perception of urban space, public art has a subtle function supporting the construction of the urban image continuously mapped out by the urbanites. Differentiating from its surrounding environment, a public artwork potentially performs as the focus of spatial perception, a landmark that is one of the fundamental elements of the image of collective urban form. Therefore, public art elements could improve the legibility of cities from a perceptional point of view (Porch, 2000; McCarthy, 2006). Public art, in this sense, is an active agent that supports the vitality of the public spaces, increases its use value and performance. Therefore, it appears as one of the critical issues within design policy frameworks of contemporary urbanism.

\section{Murals in urban fabric}

Mural painting can be considered a branch of graffiti, the drawings or writings made on a wall or other surfaces in the city fabric. It is usually practiced without official permission. Due to its 
anonymous and unauthorized performance, graffiti is classified as a marginal art. Located on the less important but the most visible facades, graffiti appropriates both the architectural elements (i.e., staircase, windows) and personifies the public space (Rey, 2019). Considered either as a form of vandalism, art, politics, or advertisement (Dovey, 2016: 201), graffiti writing has a prevalent practice in the modern city. Performed in the forgotten spaces, it is an informal form of placemaking that revitalizes urbanity through the fabric of the city (Halsey and Pederick, 2010: 96 cited in Dovey, 2016: 208).

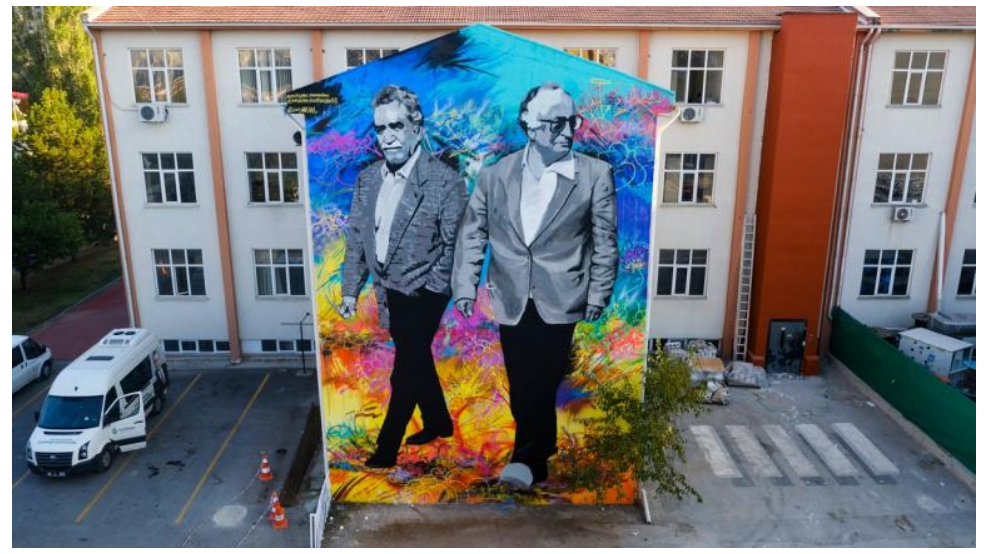

Figure 4 With the theme of 'la Hermandad' (brotherhood), Colombian graffiti artists painted Yaşar Kemal and Gabriel Marcia Marquez on the wall of a Çankaya Municipality building in 2019 in Ankara (Source: URL-7).

Like graffiti, murals are in public view, usually applied on larger surfaces mainly through the legal permissions, within the knowledge of the owner(s) of the buildings. Murals require more comprehensive processes than graffiti or other surface applications such as stencil or tag applied to larger surfaces. It can also be applied to public buildings to provide social awareness (Figure 4).

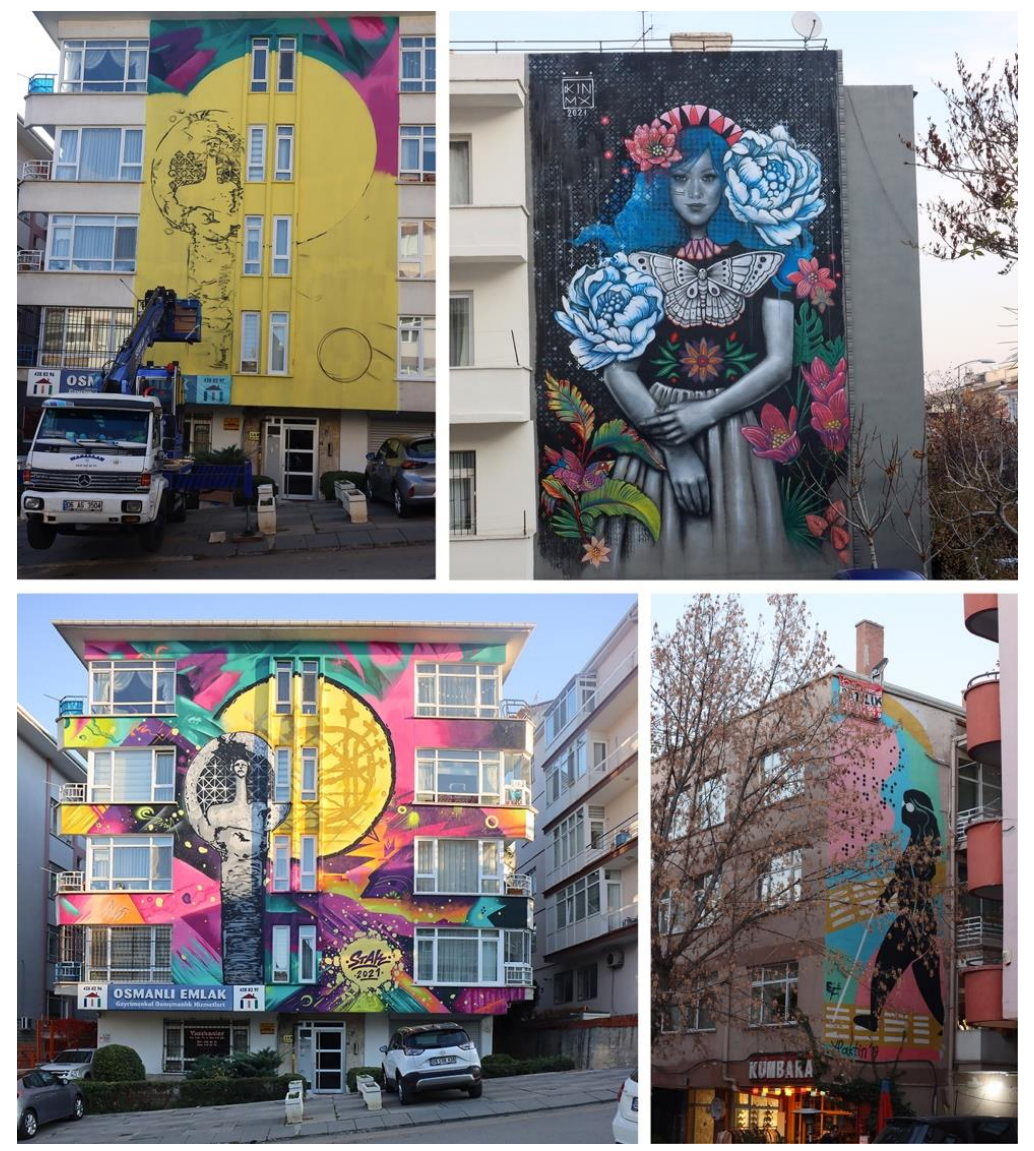

Figure 5 Some applications within the neighborhood fabrics of Ankara (Source: C.G. Yaşar's personal archive, 2021). 
In addition to its application on public buildings, utilizing the facades of the ordinary buildings within the neighborhood fabric has become common in Turkey's metropolitan cities. (Figure 5) Such a trend goes along with the socio-political tendencies as stated above. Unlike the advertisements, which require high accessibility positions and large building surfaces, the main reason why the mural applications are more frequent within the city's living quarters than in the central areas is that location-choice is more affordable to artists to hire facades for their temporary art performance in the neighborhoods. The emerging tendency towards the residential fabrics could be considered a positive factor that increases the quality of public space within the living fabric of the cities.

Murals' production time depends on many variables such as weather conditions and the number of the artists involved -up to 5 people depending on the coverage area of the façade- (Kramer, 2016: 117). In some contexts, they have to compete with the advertising signs that catch people's eye in daily life as the prominent element of the modern urban image (Toy \& Görgülü, 2018: 1153). To Remesar (2005), as 'ideological advertisements', murals demand the passer-by's attention in the public space ( $p .7)$. That means it requires a particular aesthetic dialogue with the people encountering the artwork in space. Making a kind of exceptional aesthetic statement within its spatial context, murals could perform better in the old urban patterns in which the sensation of the users is relatively settled. As J. Jacobs once argued, "new ideas must use old buildings" (Jacobs, 1961: 188).

Like all other types of artworks, murals need to pursue a certain level of perceptional capacity within their environment. This point gets critical especially considering the positioning of the artwork within the dense urban fabric, which suggests various perceptional conditions through its form and structure. That indicates a perspective to consider the mural as a spatial art. Therefore, one could argue that the aesthetic experience offered by the mural has to be revealed and enhanced spatially concerning the relations between the artwork and the townscape elements surrounding the artistic experience itself.

\section{Spatial perception and townscape}

The perception of urban space starts with collecting information primarily through the senses, albeit accompanied by many factors. The process includes collecting, organizing, and making sense of spatial information (Carmona et al. I., 2010: 87). Ittelson (1978) associated the concept of environmental perception with cognitive, imaginal, affective, and value aspects. At this point, the idea of 'image' comes forth. The image is then reproduced version of sight through the filter of mind (Berger, 1972: p. 9.). Despite being experienced in the same environmental context, different people can construct other images with subtle similarities (Rapaport, 1977). The image construction can be shaped according to the needs and motivations of the people in the move (Ittelson, 1978). For this reason, perception of space and image construction could be characterized as an intersubjective phenomenon.

In this context, Lynch (1960) defines the essential elements of the urban image (i.e., edge, node, district, path, and landmark) and describes the act of environmental perception within a rational framework. Lynch (1960) explains the relative existence of different urban landscape elements as follows: "A great landmark may dwarf and throw out of scale a small region at its base. Properly located, another landmark may fix and strengthen a core; placed off-center, it may only mislead." (pp. 84). Accordingly, visual perception is considered as a process of making sense that is realized with the close relationships between the elements, which, in turn, characterizes a specific spatial pattern.

G. Cullen (1961) introduced a similar perceptual approach in his seminal work, 'The Concise Townscape'. Cullen (1961) argues that a temple can be defined by itself with all its qualities. Still, it can be shifted to a completely different level of perception with relatively small buildings located 
next to it (p.10). That goes parallel to the relational nature of the elements of the urban image indicated by Lynch (1960). Then, the relational position of an urban component within the larger environmental context essentially conditions the internal quality perceived by people. In other words, we can conclude that the visual awareness of new elements placed in the urban fabric could be ensured by considering their environmental characteristics.

Page | 154 As Arnheim (1969) states, the human mind is evolutionarily susceptible to changes in appearance (pp. 36). Considering that the perception of urban space is mainly experienced by the pedestrian or driver in motion, one could also argue that the holistic visual perception of the city is primarily characterized by the spaces of mobility, the so-called motionscape (Çalışan, 2011). In other words, "the moving view is the primary way in which we experience our environment today" (Lynch, 1972: 185). Spatial perception processes based on movement are experienced within specific sequences. In this regard, the more continuous relations between the townscape elements sequentially perceived by the mobile observer, the more coherent image of the space would be constructed by perception. Therefore, it is possible to assume a strong relationship between movement and vision. Cullen (1961), in this regard, developed a coding system of visual documentation by experiencing spatial perception from the human eye. The proposed model called 'serial vision' is used for examining the entire perception of space in motion, all along with the changing townscape qualities during the movement. The method has gained wide acceptance within morphological studies based on urban perception.

The imageability of physical objects, which implies the availability of a strong image in mind, is delivered by the condition of visibility. The imageability of urban elements increases the probability of being noticed and remembered within their spatial context. Accordingly, Appleyard (1969) defines the act of recall on four building attributes: imageability, visibility, its role as a setting for personal activities and use, and its cultural significance to the population at large. (pp. 134).

Imageability of a physical environment, the capacity of space to enable people to construct a holistic image on that spatial setting, highly depends on the spatial form that suggests a legible structure through its perception. A clear characteristic relationship between the spatial elements (i.e., buildings, spaces, and landscape features), in this sense, does steer not only a total image of the spatial pattern but also a specific recognition of the particular elements within the complex environmental setting, as well. What we can see in Appleyard's (1969) conceptualization of the 'imageability' of a building is the distinctiveness in its physical form conditioned by both the singular attributes (i.e., contour, size, shape, surface) and the relational properties (i.e., signs around the building). In this regard, the perceptional capacity of an urban element (including a public artwork) should not be simply considered with its superiority over the other elements in the same setting. It needs to be revealed contextually and relationally. That leads us to a morphological framework dwelling on the characteristic relationships between the form elements in an urban fabric. Such a perspective would suggest a relevant basis for investigating the public arts' perceptional quality in the urban fabric.

As part of the domain of morphological research, 'perceptual morphology' concerning the built environment with a direct reference to the sensational experience of man in space (Carmona et al., 2010: 111), in this framework, could be considered an essential layer of analysis. Finding its theoretical basis in Porteous (1977), perceptual morphology assumes the cognitive capacity of the human mind, which interconnects, structuralizes, and processes the environmental stimuli received from the built fabric. Considering the public artworks as an integral part of the townscape concerning their potentiality in the collective imagination of space, one could set the systemic relationship between the townscape elements and the artworks in public space regarding the imageability of the public art. Therefore, in that paper, the authors introduce townscape as one of the significant layers of analysis in recognizing artwork (i.e., murals) in the urban fabric. 


\section{Recognition of the mural in the urban fabric: A morphological analysis}

To elaborate on the conditional (if not causal) relationship between the public art and the spatial quality of urban form, which provides peculiar accessibility structure and volumetric 'stage' on/in which the artistic performance/artwork locates is to be studied on an analytical basis. To that end, the paper suggests a framework that involves configurational and townscape characteristics of the urban form concerning the location and spatial setting of the murals in the urban fabric. For that purpose, Yeldeğirmeni, a central neighborhood in İstanbul, Turkey, has been selected for the analysis. Following a brief information about the site, the findings of Space Syntax, visibility, and townscape analyses will be presented, respectively. Via the matrix involving the results of analyses, the critical morphological aspects to ensure the perceptional capacity of the murals will be discussed.

\section{The spatial context}

Having a very central location in Kadıköy, one of the oldest districts in Istanbul, Yeldeğirmeni is a mixed-use neighborhood composed of the dense fabric of the typical apartment buildings. Since it has proximity to various central areas of the city (Figure 6), the neighborhood's daytime population usually exceeds its settled population of 12800 people (according to the Turkish Statistical Institute's 2020 census data). With a high level of accessibility, therefore, Yeldeğirmeni is one of the neighborhoods having strong recognition in the city. Such locational quality of Yeldeğirmeni has conditioned the recent transformation of the neighborhood in terms of public art, and therefore, presented a relevant context to be discussed within the current paper.

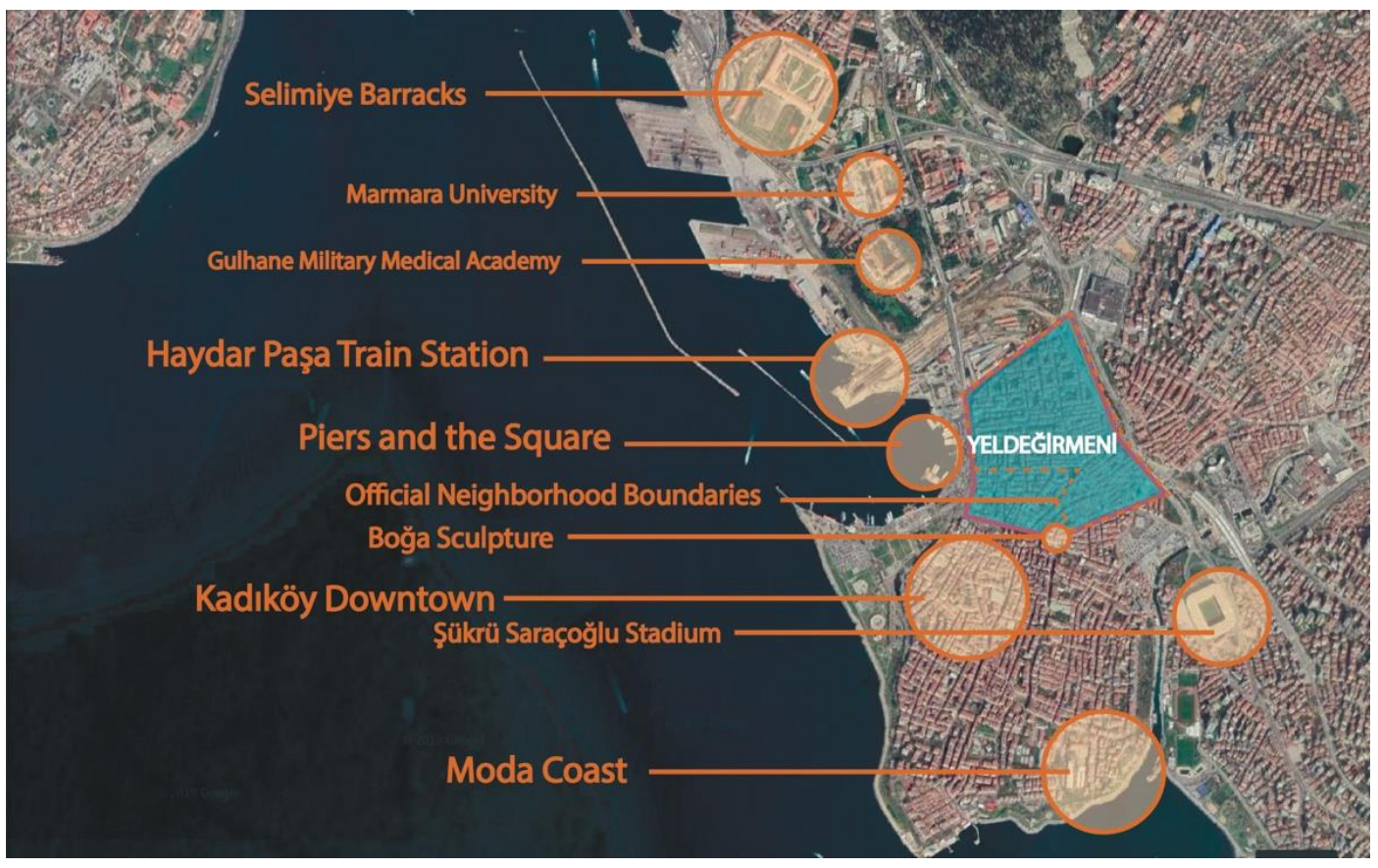

Figure 6 Location of the site in Kadıköy District, İstanbul, Turkey.

Having composed of derelict and unsafe public spaces with the lack of necessary social and physical infrastructure, Yeldeğirmeni used to have a negative reputation (mentioned as the 'back quarter' of Kadıköy) up until the early-2000s (Arısoy, 2014). Nonetheless, the multicultural community and the inherited building stock having many historic buildings were the opportunities for the future transformation of the area. In that context, the neighborhood became subject to a series of projects within the revitalization process executed by Kadıköy Municipality in cooperation with the Foundation for the Protection and Promotion of the Environment and Cultural Heritage (ÇEKÜL) in 2010. 
Page | 156

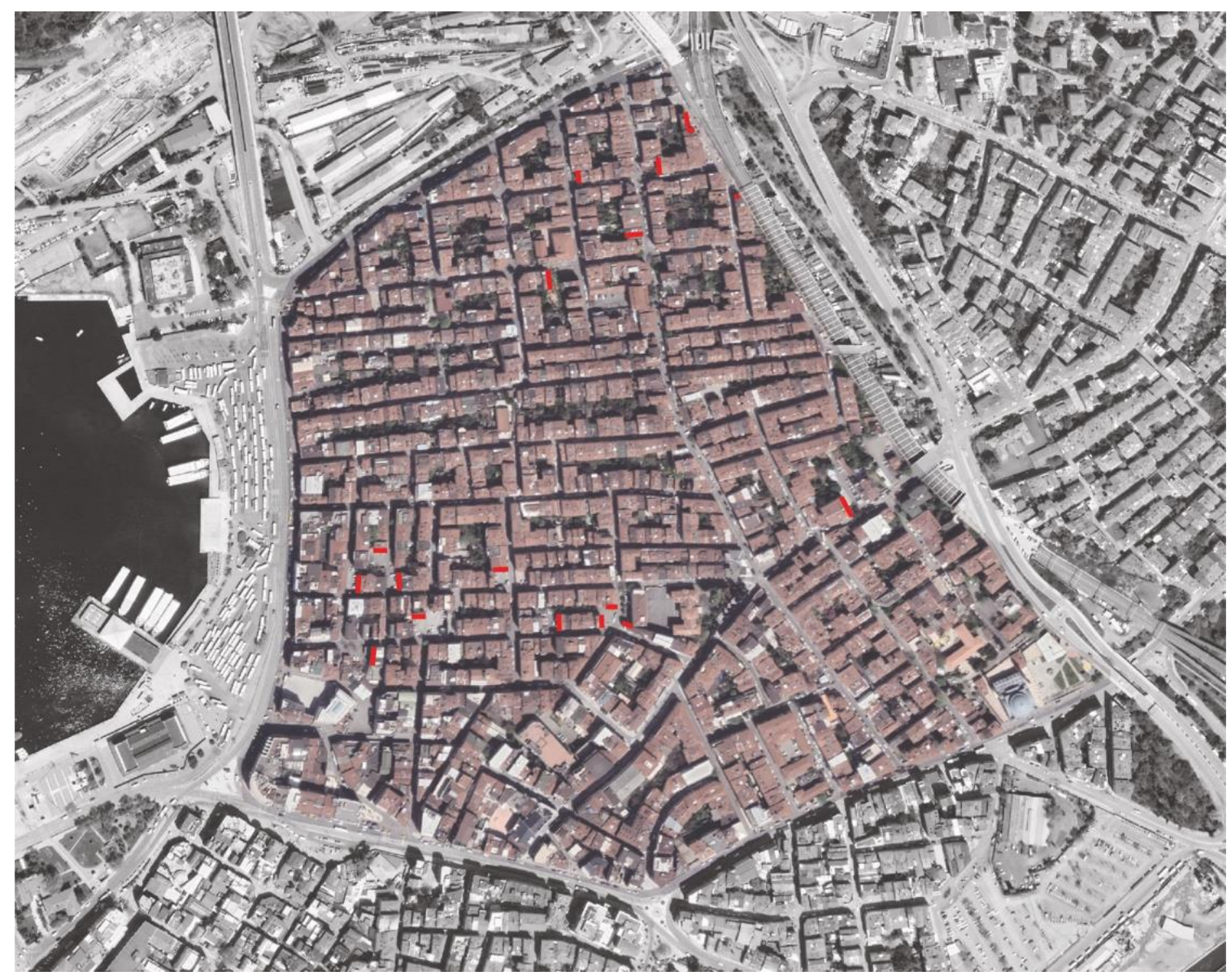

Figure 7 Distribution of the murals made after the Mural Festival in Yeldeğirmeni in 2012.

In that process, the Istanbul Mural Festival has turned out to be the leading event supporting neighborhood revitalization. Having been introduced as one of the projects in 2012, the mural festival led the execution of 18 murals on the buildings' blind façades in different locations within the fabric. (Figure 7) Since its first application, the residents and venue users have highly appreciated the artwork, and the festival has turned into a regular event repeated every year.

Considering the perceptional capacity of the public art, the amount and extent of the application of the murals in Yeldeğirmeni suggest an appropriate basis for morphological research. With the analysis presented below, the authors tend to reveal the relative capacity of the murals accessed by the public. Then, the correlation between the level of recognition and the morphological attributes of the spaces in which the murals are located will be discussed.

\section{Findings}

To present a holistic view of perceptual morphology, the fabric is analyzed first concerning its configurational characteristics. At this stage, the axial integration pattern of the area is visualized by the Space Syntax analysis. That aims to see the relative positioning of the murals in terms of their centrality within the overall street pattern. Then, the same scalar framework is utilized to expose the visibility pattern of the urban fabric in which the buildings with murals are located. Thus, the compositional quality of the collective urban form is depicted concerning the visibility of the spaces.

Accordingly, the axial integration map shows that the area has higher centrality at its southern edge defined by the main street. In addition to that, the continuous axes with relatively high integration levels penetrate the core fabric and make the neighborhood accessible from the outside. (Figure 8, left) Then, the Isovist analysis represents the overall quality of inter-visibility of the spaces embedded in the fabric. As understood from the color-codes of the mapping (the bright 
zones indicate the high visibility, as opposed to the dark-colored zones), the fabric is composed of a few 'hot spots in the form of junctions with higher visibility. (Figure 8, right) The murals located close to those junctions have a relatively higher potentiality to be perceived by the people walking on the street network.
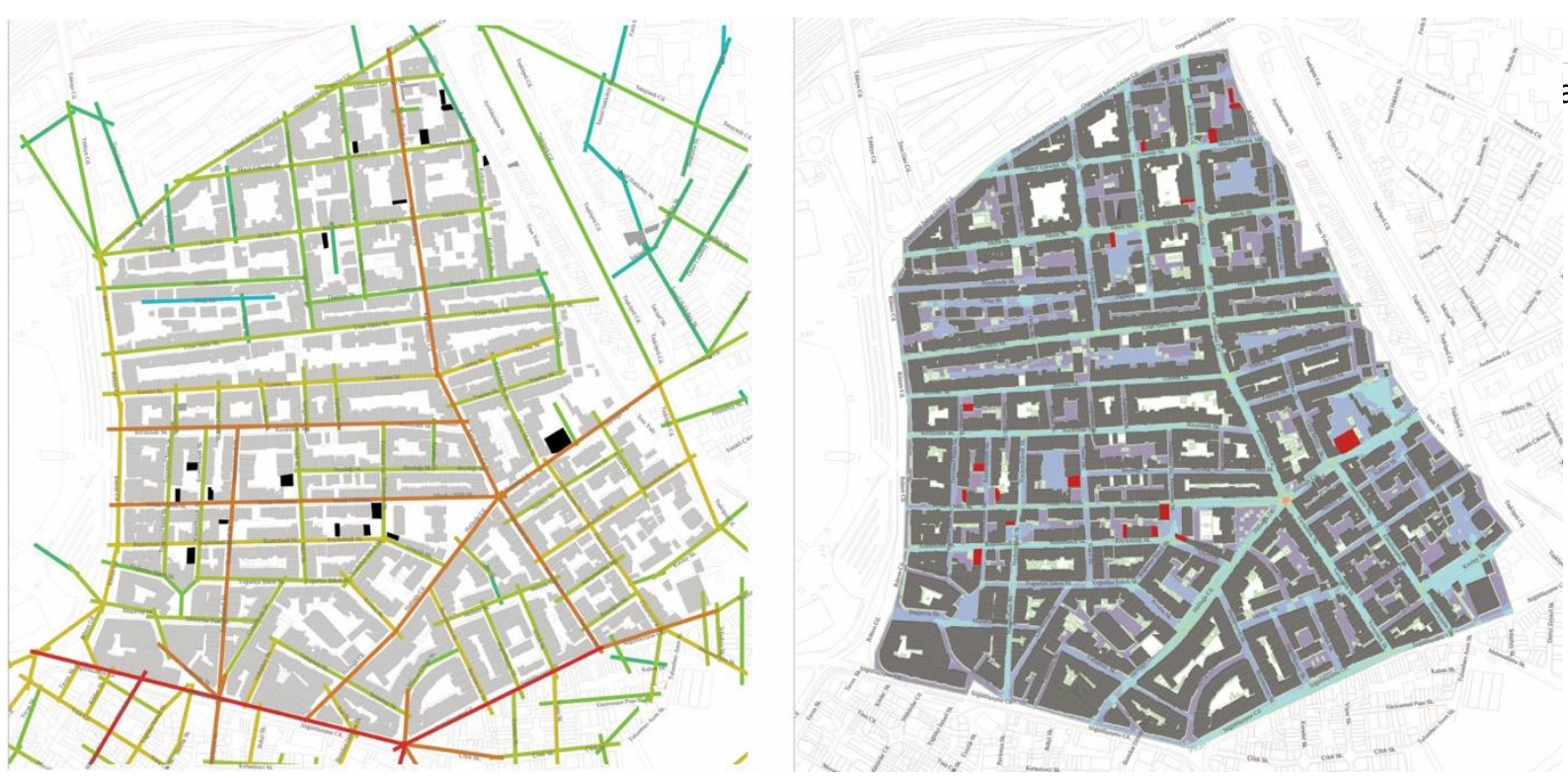

Figure 8 Maps of axial integration analysis (left) and the visibility pattern by Isovist analysis (right)

Following the configurational analysis of the whole neighborhood fabric, the townscape analysis reveals the mezzo-scale morphology of the area regarding the perceived quality of the murals' close vicinity. Cullen's (1961) townscape method and terminology are utilized for the analysis. Accordingly, serial vision is employed as a technique in the cases of the murals' spaces where the perception is subject to change through the movement on the street. The townscape qualities are mapped out with illustrative photos taken at eye level. For the analysis, nine townscape features are specified as the key indicators of spatial perception of the murals in the urban fabric. While six concepts are borrowed from the existing literature provided by Cullen (1961), the authors suggest three of them from the same perspective.
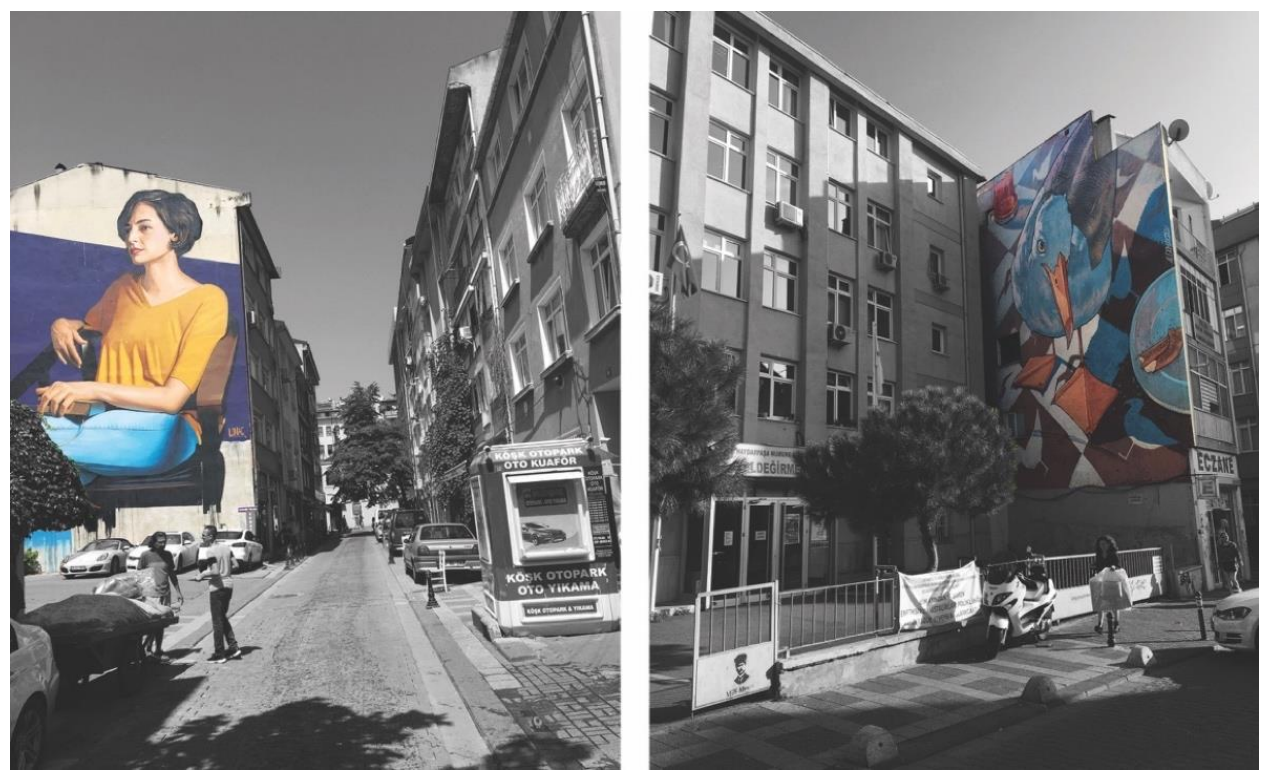

Figure 9 The singular image represented in an exaggerated size creates a dramatic visual effect on the street (left), the detailed figure on the mural increases the grain of the perceived texture of the street. 
The wall: As one of the main elements characterizing the image of a street, the blind façade is not only the vertical surface of a building but also a potential canvas on which the mural is applied. As Cullen (1961) discussed, the few blind facades that appear as empty vertical surfaces in the building fabric could suggest a distinctive 'wallscape' and might significantly differentiate the perception of the urban space (p. 155). In a dense urban fabric composed of buildings with articulated building facades, the cityscape is filled with many architectural details that make the overall perception of the environment much more intricate (Figure 9, right). As observed in the site, the magnitude of the distortion involved in the representation by the mural tends to create a dramatic effect in perception, and therefore, evokes a sense of surprise (Figure 9, left).
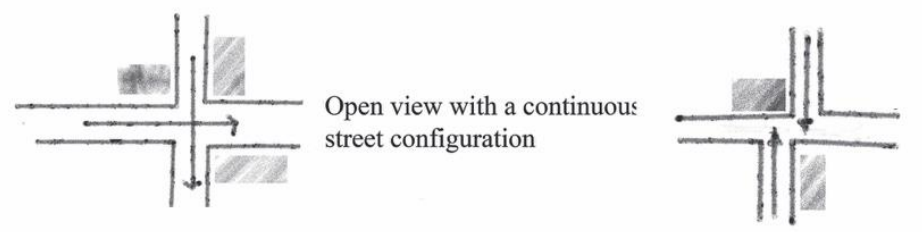

Closed view with a staggered street configuration
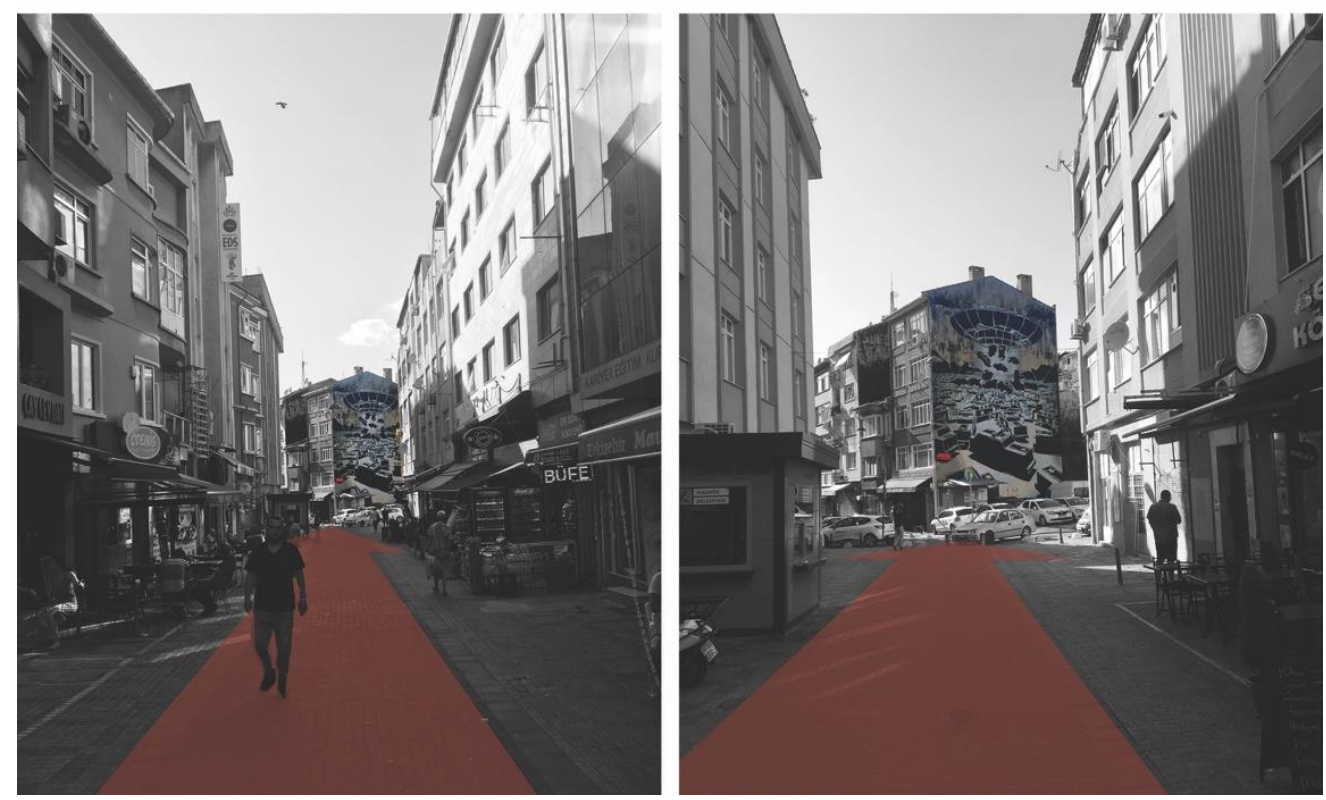

Figure 10 The staggered configuration of the street pattern generates the interrupted view that enables a better perception of the mural if it is located at the terminal point of the view corridor.

Closure: Cullen (1961) states that the closures created by the non-continuous segments of the street divide linear city systems into visually 'digestible' and consistent quantities (p.106). In this way, the sense of movement's progress would be preserved in the course of movement. The points of closure have a high perception level. In the dense urban texture, especially on narrow streets, it might be hard to visually capture the building facades entering in the view angle of the people on the street. Such spatial condition negatively affects the visibility of murals usually located on the flank fronts of the buildings. If the mural is situated in a closure point, it gains higher visibility within its fabric (Figure 10). 

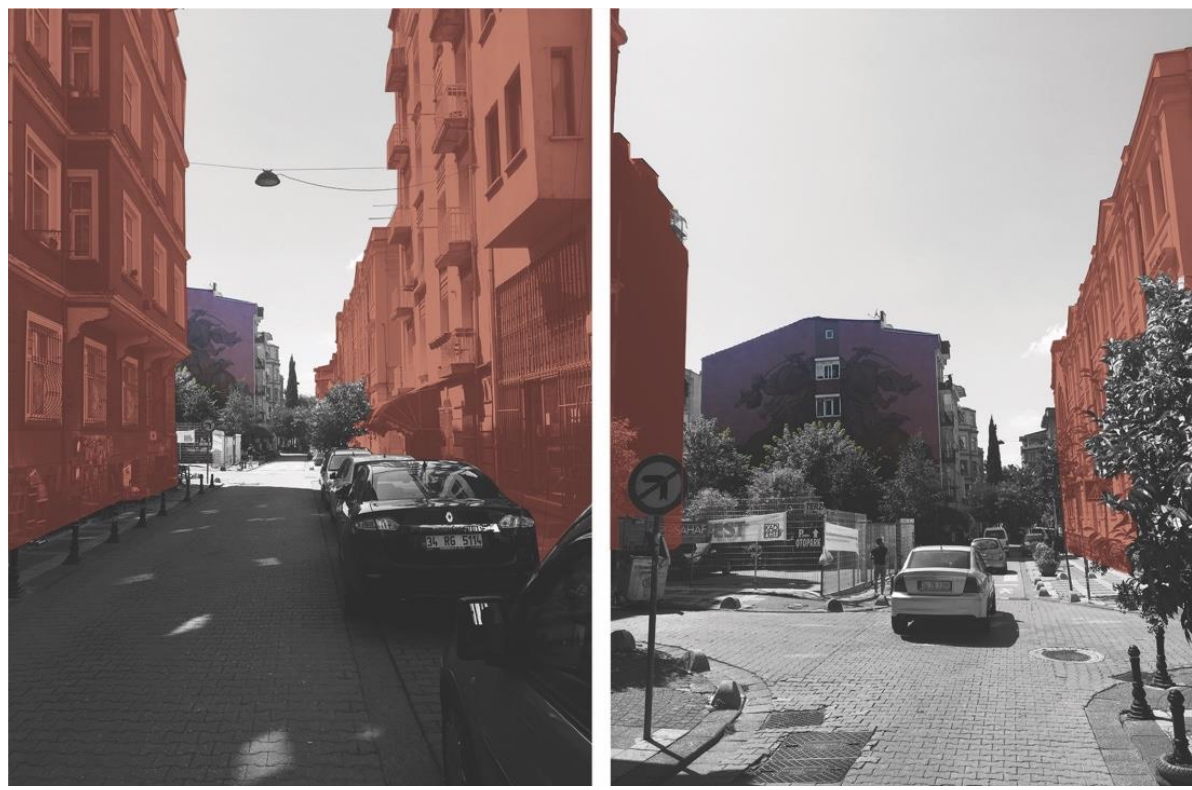

Page | 159

Figure 11 The serial vision on a selected street in the neighborhood exemplifies the change in the enclosure level and a perceived increase in the visual manifestation of the mural in the fabric.

Multiple enclosure: According to Cullen (1961), a space can exhibit separate enclosures combined into one inter-penetrating whole (pp. 30). The concept of 'multiple enclosure' could be observed in any street pattern on which the relationships between the buildings tend to differ. In this context, it is expected that the average view angle tends to decrease when the level of enclosure increases. In the street network, such an inverse relationship might change dynamically. That means with the changing level of enclosure, the visibility of the streetscape is transformed. While progressing on the street, the changing enclosure level stimulates or ceases the perception of the space. When the buildings define the space recess, the possibility of perceiving a larger surface of the environment visually increases. If the murals are located at the point of transition from enclosed to open space at the direction of the move, then it receives greater attention with increased visual recognition of the public art (Figure 11).
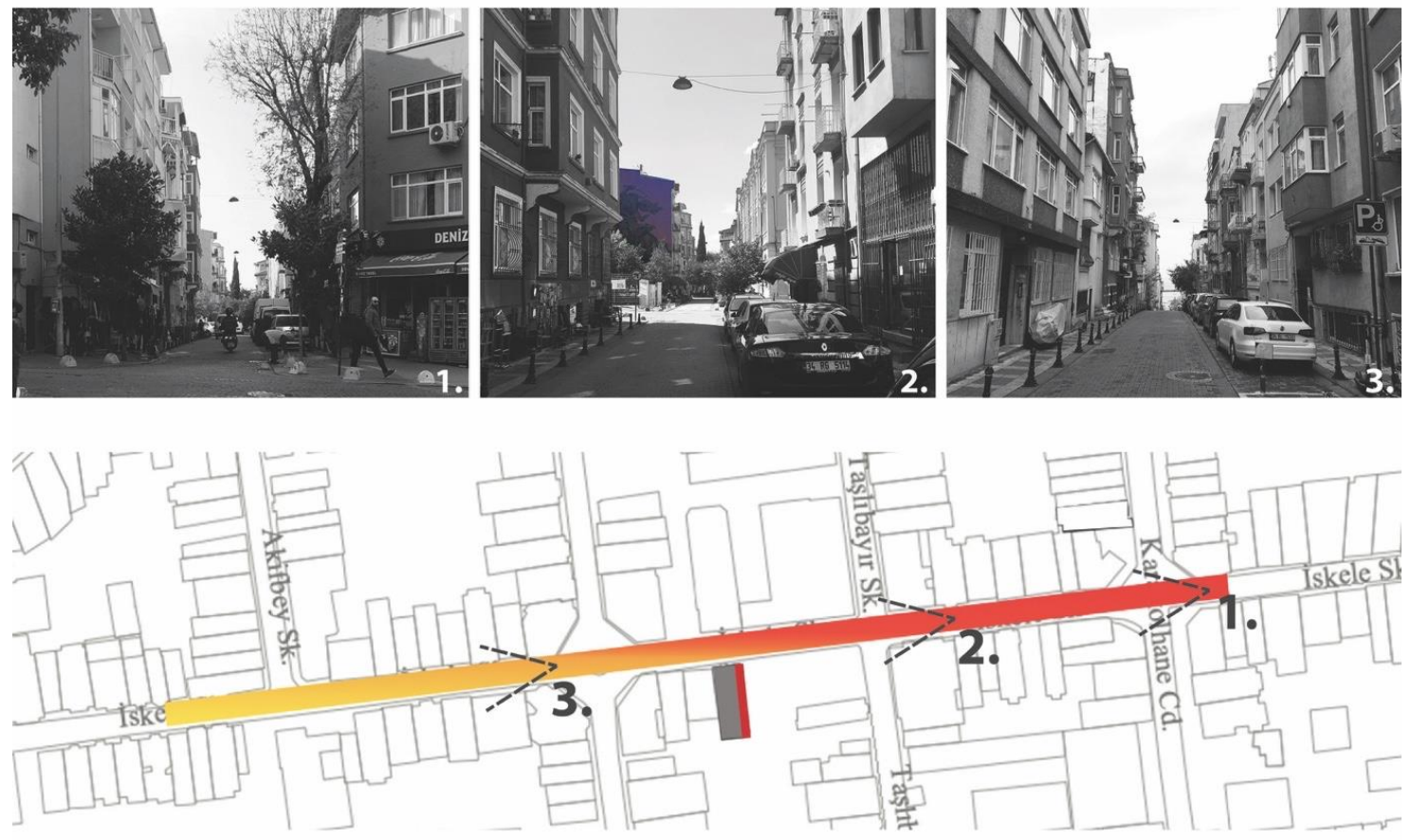

Figure 12 In the given context, the punctuation point implies a visual transition from commercial to residential fabric (below), and the changing spatial rhythm (above), accordingly. 
Punctuation: To Cullen (1961), the built environment is articulated into identifiable parts which initiate the sense of here and there throughout the flow of the body in urban space. Such distinction is sometimes restricted by artificial elements such as narrows and closures (pp. 35, 182). Such an effect would also be generated by the visual aspects and the physical components of the built environment. Considering the typologies suggesting different building dimensions, we can specify the particular visual rhythms along with the street segments with distinct building typologies. Different articulations, even on the façades of the same building types, could create individual visual segmentations perceived through the movement in the network. Then, the changing points of the sequence of visual rhythms indicate a kind of punctuation, the terminal points that give way to another visual series. The spatial perception at those points raises significantly when the functional character of the street is also changed. Accordingly, as a space consists of similar images, any transition in the visual pattern during the movement stimulates the perception of the people experiencing the space. The murals coinciding with the so-called punctuation points have the higher potentiality to be perceived if they are visually accessible at a certain distance (Figure 12).

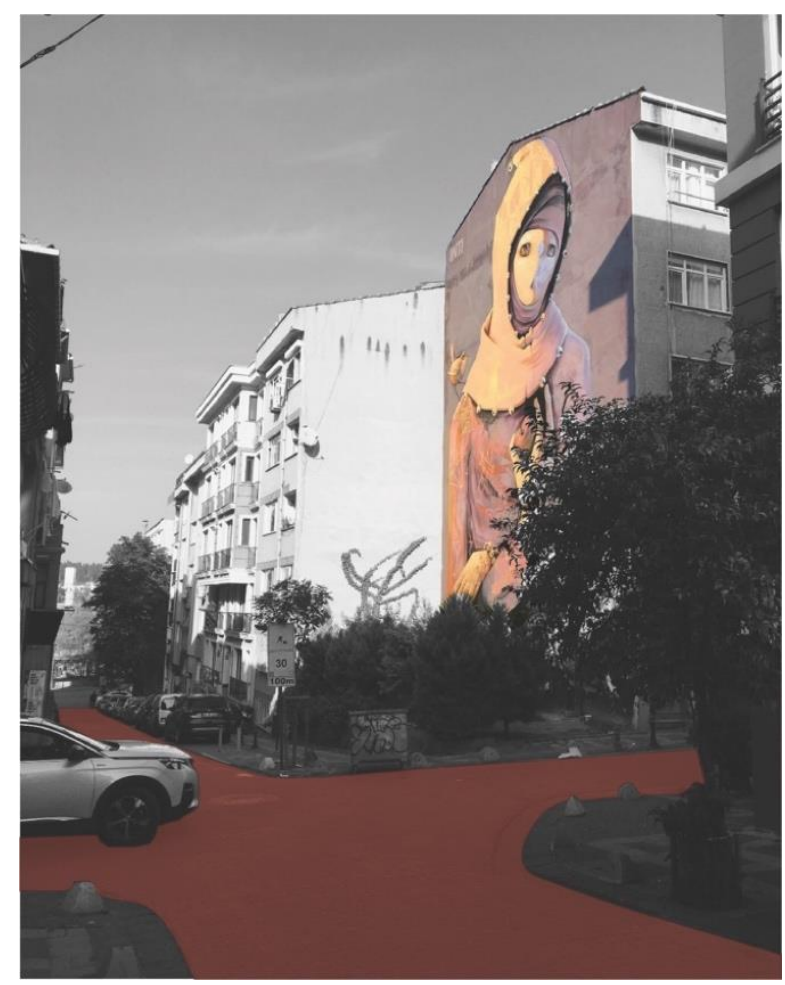

Figure $13 \mathrm{~A}$ street junction on which the mural is positioned with high perceptual capacity.

Focal point: Cullen (1961) identifies the 'focal point' as a vertical artifact -a landmark in Lynch's (1960: 78-83) term- coupled with the enclosure of a central space that pinpoints the spot of the common perception (pp. 26). Primarily located at the intersection of the streets as the node of the network, focal points could be considered the space terminating the flow and focusing the attention of the passenger inflow (Çalışkan, 2011: 330). Then, street junctions are unique points for the environmental perception in the cities. Due to the actual need to control both sides of the traffic flow in at least two street directions, the passengers are awakened at the time of crossing. At that stationary moment, the built-up elements could potentially have a higher chance of being noticed than what reside along the street. Moreover, the increased level of spaciousness makes the buildings around the junction more visible with a wider view-angle. (Figure 13) Creating a divided continuity along a single route, junctions determine a series of starts and end through the movement. This is what makes them perform as the focal point by which any possible presence of a mural makes it more perceivable. 

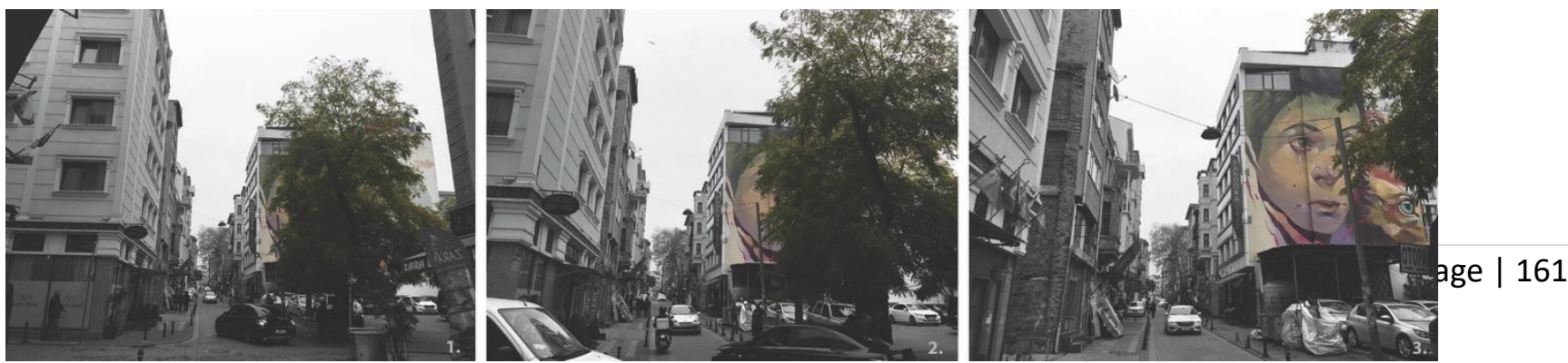

Figure 14 Within the serial vision, while the tree screens the mural standing behind from a distance, the successive change in the observer's position makes the mural visible without any barrier: The early stage, in which the mural is barely seen, stimulates the sense of anticipation, and makes the perception more effective.

Anticipation: The disorderly relationships between the townscape elements do not necessarily generate negative visual sensations in the urban environment. For instance, in the course of a movement in urban fabric, though a vertical element (i.e., a tree or a clocktower) disrupt the visibility of another townscape element from a certain distance when the proximity changes between the object and the observer, the changing view discloses the element behind another. During the approach to the piece behind, the observer would anticipate what is forthcoming. Explaining it regarding the barely observed facades of the buildings behind the other buildings in traditional fabric, Cullen (1961) describes the sense of curiosity as anticipation within space (pp. 49). In the context of the mural within a dense urban fabric, such dynamic visual relationship between the elements potentially enriches the aesthetic experience of the public art (Figure 14).
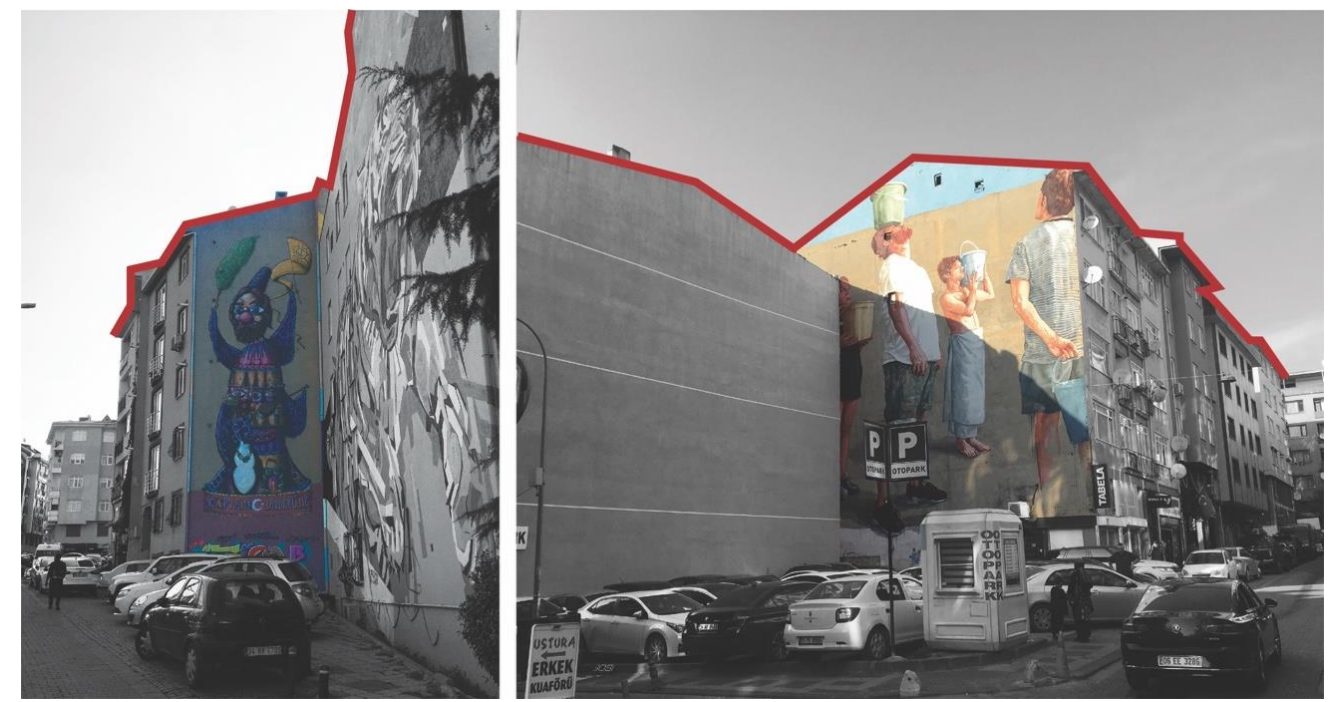

Figure 15 'Protrusion', a sudden change in the alignment of the frontal facades of the buildings, generates a highly perceived surface for the mural.

Protrusion: Within the traditional urban fabrics, the relationship between the building and the street is dynamic, and therefore, generates a rich visual setting. Admiring such visual complexity of the traditional urbanism, Cullen (1961) argues that "any slightest deviation in alignment and quite small variations in projections and setbacks have a disproportionally powerful effect in the third dimension" (pp. 17). This might also be the case within the planned urban fabrics subject to some incremental transformations. In townscape terms, the observed diversity in the positioning of the buildings characterizes the perceived continuity of the facades along the street. In this context, when a building overflows the common frontal setback within an urban block, or the adjacent building recesses its front façade after being redeveloped, then the lateral façade of the building would have a higher perceptional capacity. That makes the spot suitable for the murals aiming for high recognition by the public (Figure 15). 
Page | 162

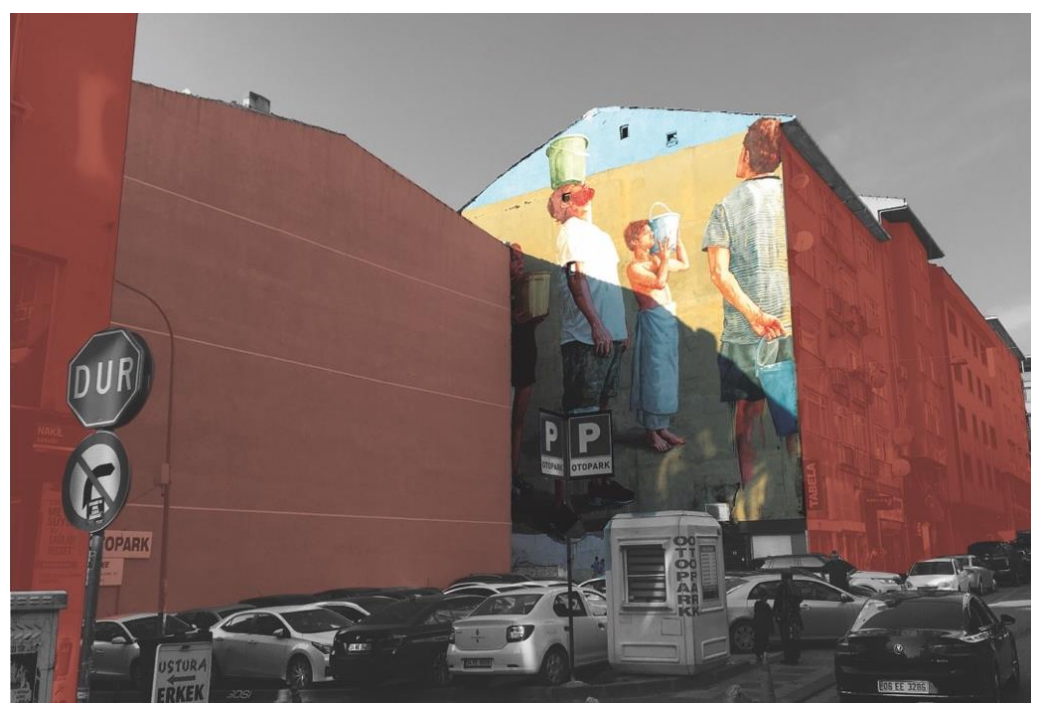

Figure 16 The blind facade of the building on a street wall creates a perceivable contrast within the streetscape. The nearby positioning of the mural takes advantage of that position for the desired perceptional capacity of the public art.

Juxtaposition: Cullen (1961) defines the state of a direct relationship between the contrasting visualities (i.e., urban vs. natural, pastoral vs. industrial) that could be found in and around the city fabric (pp. 60). The facades of the buildings involved in the formation of urban fabric expose different characteristics in terms of material, openings, layering, color, and articulation. The contrasting surface quality of the facades would be considered a common condition in the townscape of modern cities. When the distinction in single or multiple properties is high, such contrast causes either enrichment or disharmony within the urban environment, depending on the contrast level. In each case, the visual elements positioned between the contrasting facades tend to be more pronounced than any other location on the linear façade composition. That would be a desirable condition for applying a mural within the given fabric (Figure 16).
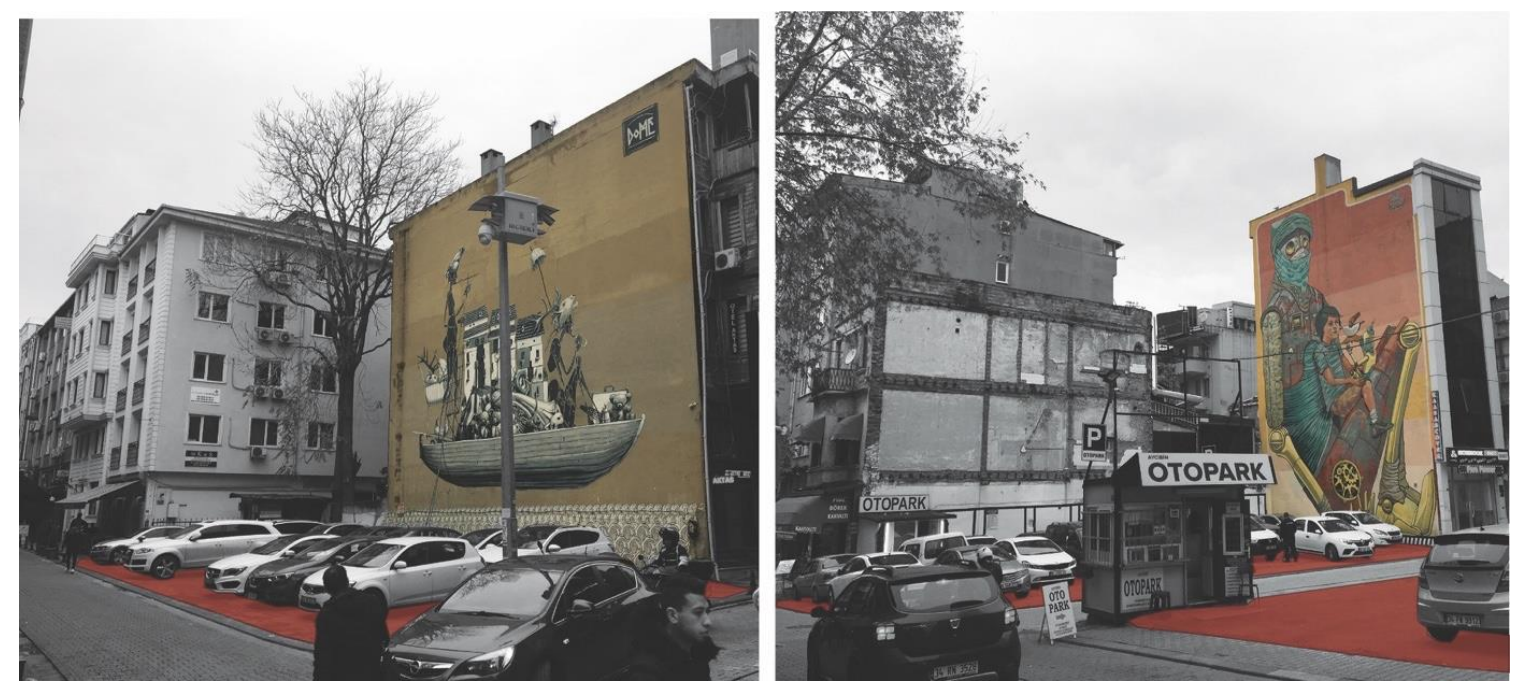

Figure 17 An observable match between the parking lots and the murals: such a coupling condition creates a characteristic setting.

Match: Some spatial settings condition the adaptation of various programs into the urban fabric. For instance, street corners invite corner shops or cafes; continuous facades could generate retail development, etc. Regarding the public art, the spatial voids that already exist in the city fabric provide a suitable condition for the murals to be applied on the aligned facade of the buildings. In the context of Yeldeğirmeni, the observed match between the parking lots and the murals signifies such a condition that increases the easy recognition of the artworks within the urban fabric (Figure 17). 


\section{Discussion}

Following the morphological analyses to reveal the perceptional capacity of the spatial setting in terms of network integration, visibility, and townscape characteristics, a survey was conducted by questioning whether the participants have visually experienced the listed murals in the neighborhood. The survey involved 50 people who either live or work in the neighborhood. Within the survey, the pictures of each mural were shown, and the participant's responses on personal awareness were recorded. The main aim of the survey is to test the expected correlation between the spatial characteristics and the actual level of public recognition of the murals as public artworks.

The area is divided into three-character areas with distinct functional and experiential qualities to encode the murals. (Figure 18) Accordingly, zone A, on the one hand, is characterized by heavy vehicular and pedestrian traffic along with a mixed land-use pattern due to its proximity to the urban waterfront and the pier. Therefore, the area has many open parking plots creating voids in the dense urban fabric. Along with the blind facades of the surrounding buildings, those unbuilt parcels generate a series of places affording high visibility for the murals. That's why; the highest number of murals are concentrated in this zone. On the other hand, zone B is characterized by the high-street backboning the area with all the recreational facilities (i.e., cafes and restaurants) concentered along the route. This essentially increases the use-value and the experiential capacity of the areas. Finally, zone $\mathrm{C}$ is a high-density residential area with few commercial functions and low traffic. Five murals in that zone are located close to each other.

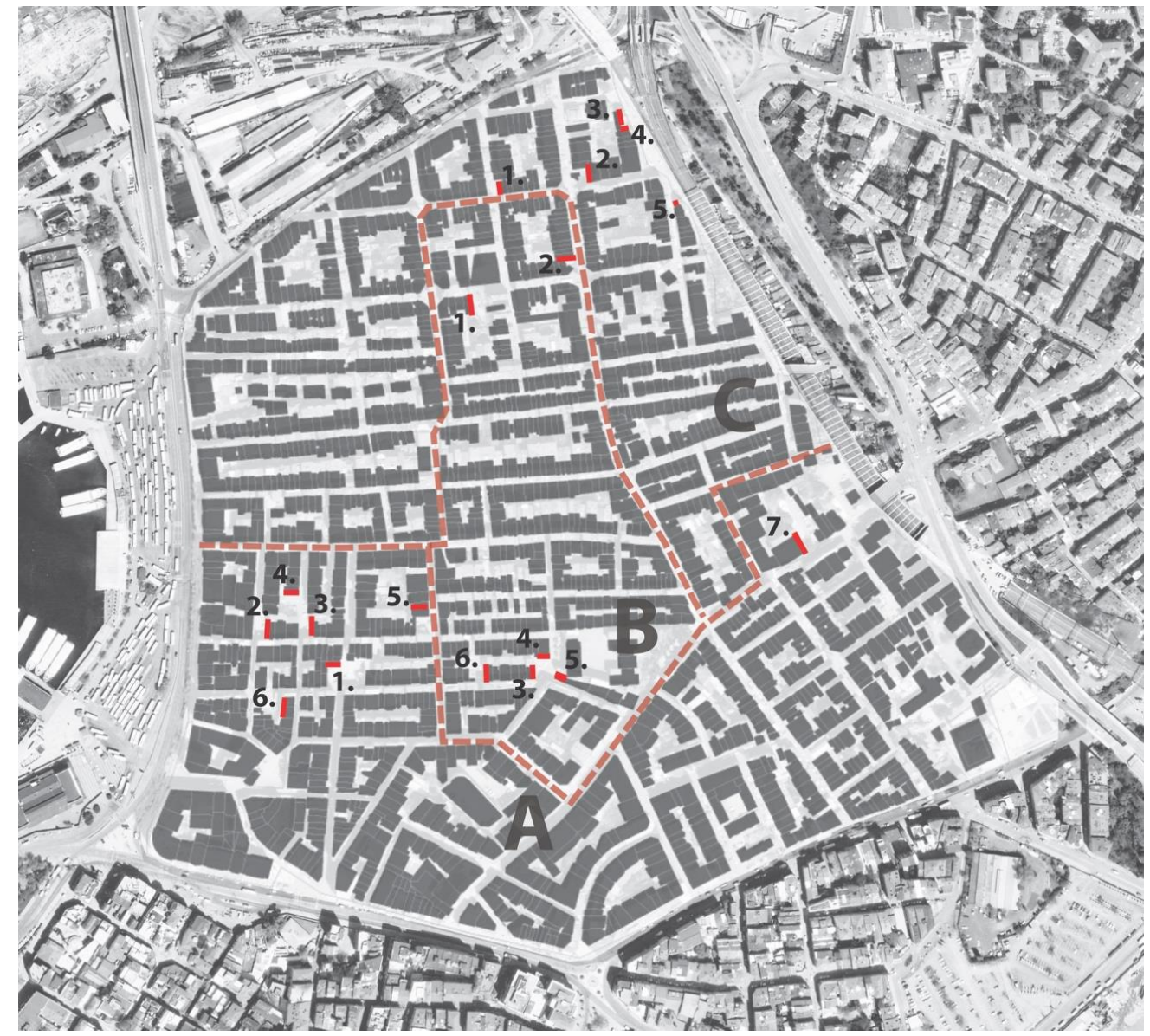

Figure 18 Character areas in Yeldeğirmeni Neighborhood and the location of the murals.

Accordingly, the survey results (the percentage of the people who responded positively on recognizing a given mural) are plotted in the matrix along with the analyses scores and the specified townscape characteristics of the spatial contexts (Table 1). 
Table 1 The matrix showing the results of the spatial analyses and the survey results.

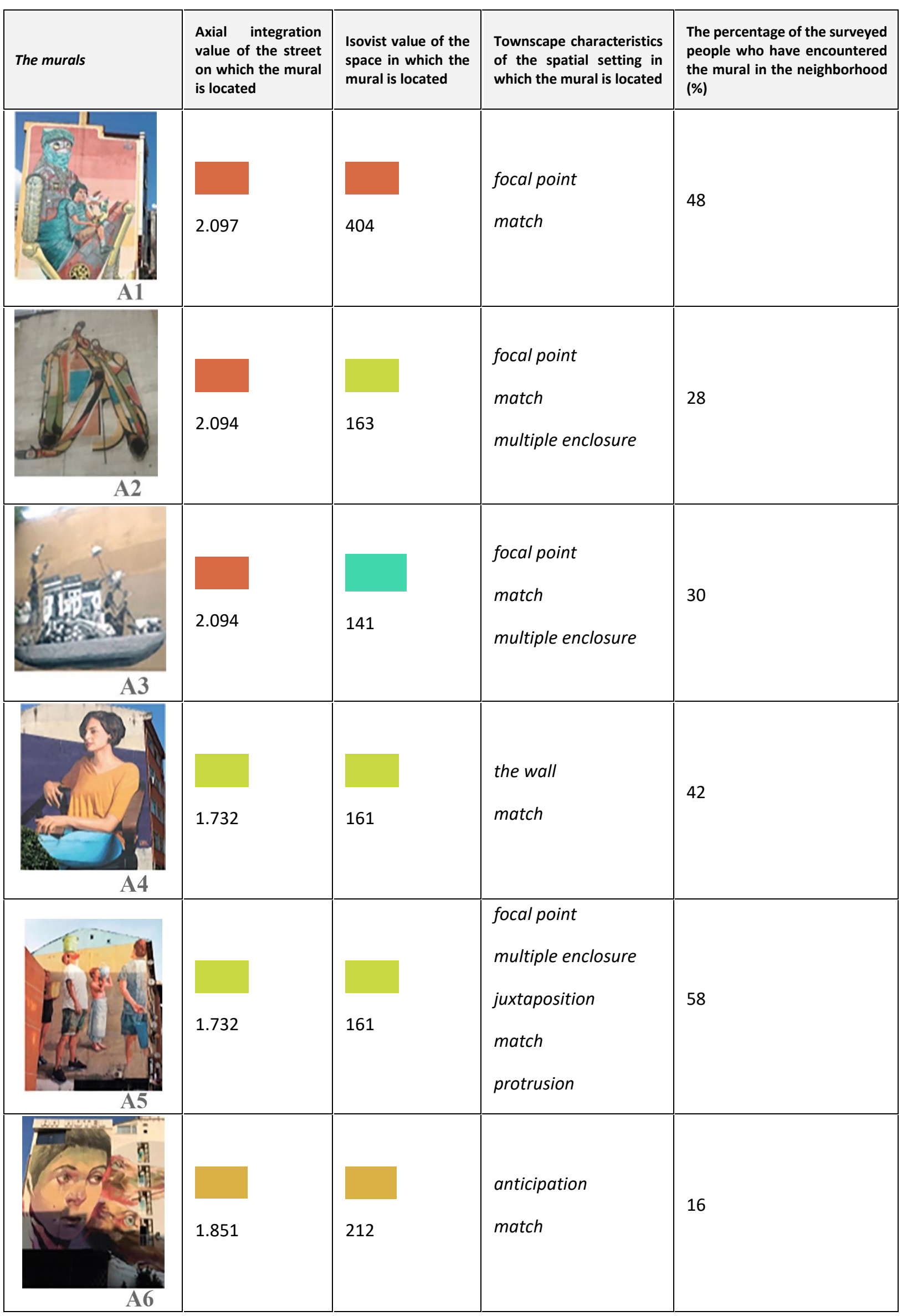




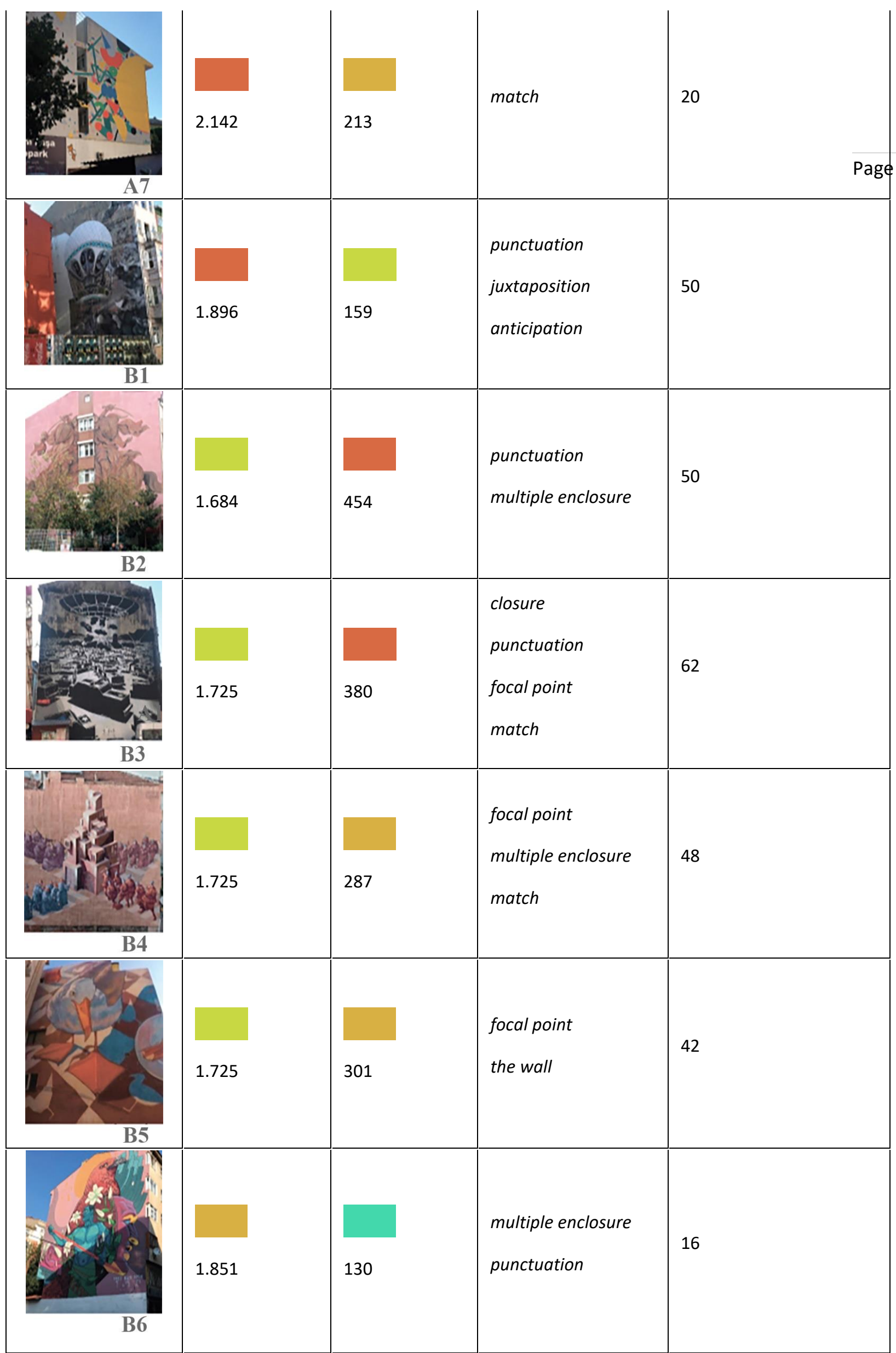


Page | 166

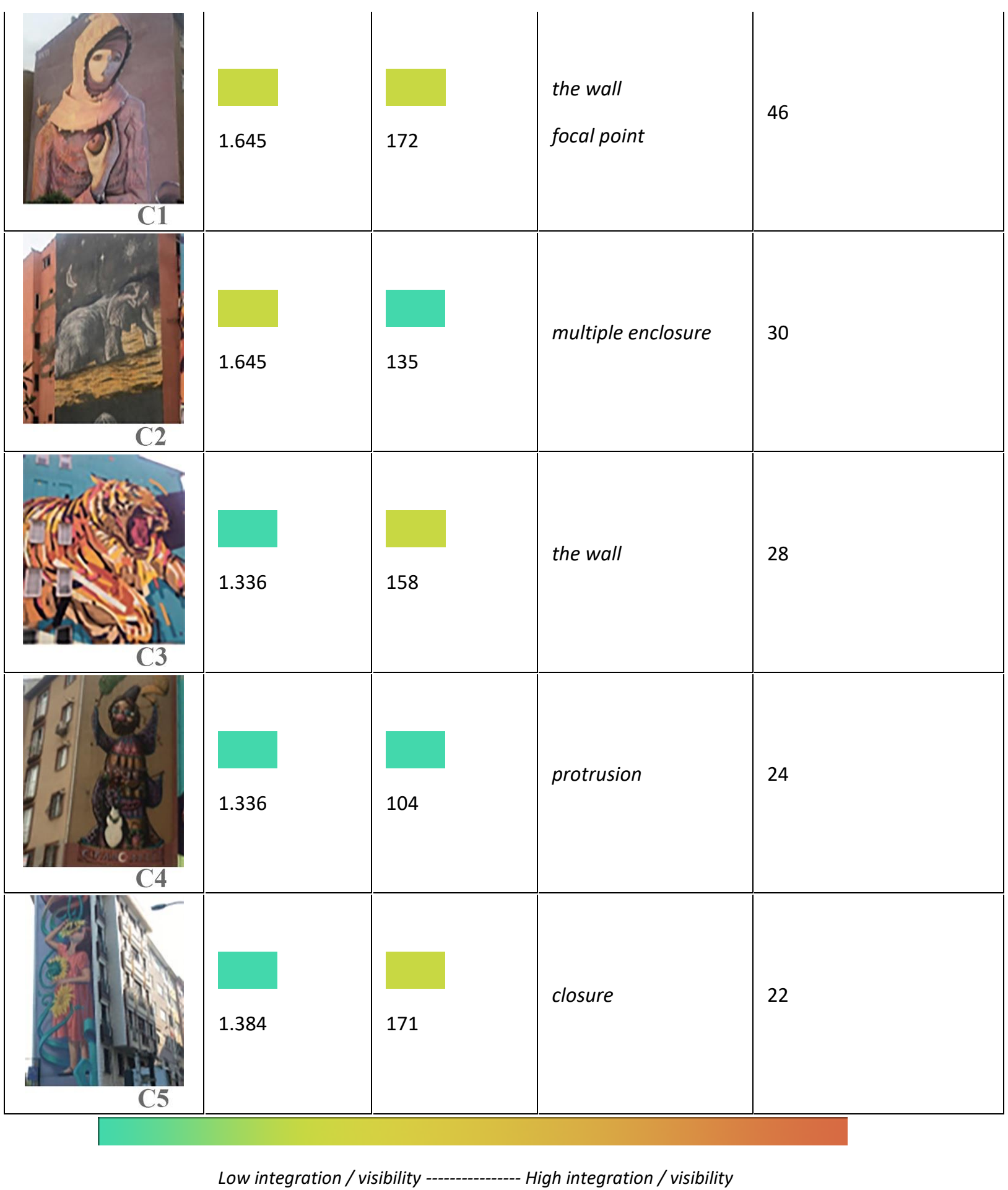

According to the survey results, the mural-B3 is scored with the highest level of recognition. The configurational analysis indicates the medium integration and a high Isovist value for the street and the space on/in which this mural is located. Examining the mural-B3's spatial context, we specify closure, punctuation, focal point, and match as the major townscape characteristics. Then, the survey results classify the mural-A5 as the public artwork revealing the second-highest recognition value. The mural is positioned on an axis with medium level of integration (like that of the muralB3) in a dense traffic area along with the townscape features of focal point, juxtaposition, match, and protrusion. In this context, located near the parking space, match is the shared characteristics of the murals having maximum recognition. Closure could be considered one of the key features increasing the perceptional performance of the artwork, since it is observed only in the case of the mural-B3, the most recognized mural in the site. Likewise, revealed only in the context of A5 (along 
with B1 as another well-recognized mural in the area), juxtaposition could be another feature providing a basis for high-level perception. Considering these two cases, one could argue that the townscape features strongly influence the perception of the murals compared to the configurational characteristics of urban spatial structure.

As seen in the table, both configurational values of the spaces in which the murals, A4, A5, and all the murals in the zone- $C$ locate render below the average in the whole area. Then, some townscape qualities get critical since the recognition levels of A4, A5 and $\mathrm{C} 1$ are above the average. Shared by different couples of the murals, match and focal point stand out as the features that could ensure the high perceptional capacity of the artwork.

Among the first four murals having the highest axial integration values ( $A 1, A 2, A 3$, and A7), A2, $A 3$, and $A 7$ are in the lowest recognition group. Except for $A 1$, the Isovist values of the former group are relatively lower within the larger group. That could imply that the high axial integration value per se does not guarantee the increased recognition of the murals. In addition, it is possible to state that $A 8$, which is the least known mural within that group, has a kind of spatiality revealing an adverse publicity condition with the billboards visually screening the mural itself. That indicates that despite having high accessibility (in terms of axial integration) within their location, murals require supporting townscape qualities for increased recognition by the public.

When we look at the murals with high visibility, we could specify $B 2, A 1$, and $B 3$ as the murals having greater Isovist values. Except for A1 considered above, B2 and B3 murals also reveal a high recognition level (clearly above the average -\%36.6-). As expected, that indicates a positive correlation between the Isovist and the perceptual capacity. Then again, though the axial integration values of the mural-B2 and mural-B3 are below the average, the visibility factor supports their public recognition. In addition, the shared townscape feature of punctuation could be considered the critical positive factor for that score.

In this context, almost all the murals in area $\mathrm{C}$, whose configurational values are below the average, reveal a low perceptional capacity in terms of the specified level of recognition. As an exception, the recognition level of the $\mathrm{C} 1$ mural is above the average despite the fabric's low spatial and visual accessibility. That would be explained by the locational townscape characteristics of the mural space as a 'focal point'. Likewise, the murals, A6 and A7 exposing the lowest range of recognition, reveal the spatial accessibility just above the average integration value. That essentially demonstrates the significance of the adequate townscape quality characterizing the space and the fact that high level of network integration does not necessarily ensure the high public recognition of the artwork.

\section{Conclusion}

It might sound somehow tautological to state that public space is the basis of public art and its performance concerning the aesthetic experimentation of people. However, if it is installed in a public space in an outdoor setting, public artwork's spatiality necessitates considering the issue from a morphological perspective. The aesthetic experience of public art is conditioned not only by the art's internal quality as an object but also by the spatial framework that the figure interacts with. Such a synergetic relationship between the artwork and the space makes the issue a subject matter of the spatial research. The performance of public art is highly contingent upon the perceptual capacity of its spatial context to attract people's movement and visual perception of itself. That also implies the procedural nature of the phenomenon in the name of 'public process', which is one of the basic features of public art. The sensory experience of public art is not limited to its actual location. It starts and unfolds through the movement towards its in situ visual presence. Such a kinesthetic experience involves the public art's close vicinity and its wider spatial setting within a contingent relationship between body and space. Then the aesthetic experience could be revealed through a series of morphological factors that condition the perceptional capacity of the public art. At that point, the authors argue that the integration of space, visibility, and townscape 
characteristics could be considered the major spatial factors for the performative quality of public art in the city fabric.

To test that straightforward argument, following the spatial analyses of axial integration (Space Syntax), visibility (Isovist), and townscape, the authors conducted a survey that includes fifty people who regularly visit and use the site. The main intention behind the survey study was to collect

Page | 168 information about the extent of people's recognition of each mural located in the neighborhood. In this way, the level of recognition could be correlated with the spatial characteristics of the particular locations where the different murals are positioned.

Theoretically, one could argue that the spaces with higher configurational capacity (in terms of integration and visual accessibility) have a higher degree of people's encounter with the public art if the space accommodates an artwork in its setting. The research reveals that despite being integrated and highly visible in a configurational manner, an urban space with poor townscape quality might suggest a low level of recognition of the artwork that the space exposes to the public. In other words, despite rendering relatively lower configurational capacities (of integration and visibility), the spaces that suggest certain townscape qualities would have higher potentiality to make the embedded artwork relatively more perceivable for the people. Such morphological indicators turn out to be the critical factor in increasing public art's desired performance. That indicates the necessity of an effective coalescence between the structural and townscape qualities of urban form, therefore, an integrative approach combining configurational and perceptual morphology.

In this context, urban design as an art of placemaking has a crucial role in empowering the sensory quality of urban form for a higher perceptional performance of the public art in our cities. Especially for the cities enacting the revitalization policies to promote the art in space, the design strategies enhancing the spatial setting towards more effective public art performances are essential. For that reason, better integration between morphological analyses, design frameworks, and the execution processes of public art should be constructed. The research, in this regard, could be considered an attempt to provide an analytical basis for a better practice.

\section{References}

Allahmoradi, M. \& Cömert, N.Z. (2021) 'A New Complementary Model for Integrating Historico- Geographical and Configurational Approaches: The Case of Famagusta', Urban Morphology 25(2), 115-36

Appleyard, D. (1969) 'Why Buildings Are Known: A Predictive Tool for Architects and Planners', Environment and Behavior, 1, 131-156.

Arendt, H. (1958) The Human Condition, Chicago: The University of Chicago Press.

Arısoy, A. (2014). Yeldeğirmeni Deneyimi: Kentsel Yenilemeye Farklı Bir Yaklaşım, İstanbul: ÇEKÜL Vakfı.

Arnheim, R. (1969 [2004]) Görsel Düşünme, Istanbul: Metis Yayınları.

Baca, J. (1995) 'Whose Monument Where? Public Art in a Many-Cultured Society', in S. Lacy (Ed.), Mapping the Terrain: New Genre Public Art, Seattle: Bay Press, 131-138.

Berger, J. (1972 [1990]) Ways of Seeing, London: British Broadcasting Corporation and Penguin Books.

Çalışkan, O. (2011) 'Motionscape: The Image of Space in Motion (An Attempt at Conceptualization in the Case of Ankara)', Journal of Architectural and Planning Research 28(4), 314-35.

Carmona, M., Tiesdell, S., Oc, T., \& Heath, T. (2010) Public Places, Urban Spaces, Oxford: Architectural Press.

Cullen, G. (1961 [2015]). The Concise Townscape, London: The Architectural Press.

Dovey, K. (2016) Urban Design Thinking: A Conceptual Toolkit, Bloomsbury: London.

Ercan, M. A. (2013) 'Kamusal Sanatın 'Kamusallı̆̆ı': Erişim, Aktör, Fayda Yaklaşımı', Ideal Kent 10 (Kentin Sanatı, Sanatın Kenti), 220-255.

Erdoğan, G. (2014) 'Mapping Street Art in the Case of Turkey: Istanbul, Beyoglu Yuksek Kaldirim', Lisbon Street Art \& Urban Creativity International Conference. Lisbon University.

Gombrich, E. H. (1950). The Story of Art. London: Phaidon.

Griffiths, S., Jones, C.E., Vaughan, L., Haklay, M. (2010) 'The Persistence of Suburban Centres in Greater London: Combining Conzenian and Space Syntax Approaches', Urban Morphology 14(2), 85-99 
Habermas, J. (1962 [1991]) The Structural Transformation of the Public Sphere, An Inquiry into a Category of Bourgeois Society, Cambridge: The MIT Press.

Hall, T. and Robertson, I. (2001). Public Art and Urban Regeneration: advocacy, claims and critical debates. Landscape Research, 26(1), 5-26.

Hall, T. and Smith, C. (2005) 'Public Art in the City: Meanings,Values, Attitudes and Roles', in M. Miles and T. Hall (Eds.) Interventions: Advances in Art and Urban Futures, Bristol: Intellect Books, 75-180.

Halsey, M. And Pederick, B. (2010) 'The Game of Fame: Mural, Graffiti, Erasure', City 14(1-2), pp. 82-98.

Hein, H. (1996) 'What is Public Art? Time, Place and Meaning', The Journal of Aesthetics and Art Criticism, $54(1), 1-7$.

Ittelson, W. H. (1978). 'Environmental Perception and Urban Experience', Environment and Behavior 10, 193213.

Jacobs, J. (1961) The Death and Life of Great American Cities, New York: Vintage Books.

Januchta-Szostak, A. (2010) The Role of Public Visual Art in Urban Space Recognition. Cognitive Maps, Open access peer-reviewed Edited Volume, https://www.intechopen.com/chapters/6752, accessed in October 2021.

Kızılkan, G. (2016) Kamusal Alanda Aykırı Sokak Sanatları Uygulamalarının Fiziksel ve Sosyal Mekâna Etkileri, MSc thesis, Istanbul Technical University.

Kortbek, H. B. (2018) 'Contradictions in Participatory Public Art: Placemaking as an Instrument of Urban Cultural Policy'. The Journal of Arts Management, Law, and Society, 49(1), 30-44.

Kramer, R. (2016) 'Straight from the Underground New York City's Legal Graffiti Writing Culture', In Ross, J. (ed.) Routledge Handbook of Graffiti and Street Art, New York: Routledge.

Kucuksahin, S. (2016) 'Turkey's artists face growing government pressure', Al-Monitor: The Pulse of the Middle East, https://www.al-monitor.com/originals/2016/07/turkey-artistic-community-come-underpressure.html, accessed in October 2021.

Kwon, M. (2010) One Place After Another: Site-Specific Art and Locational Identity, Cambridge, Mass.: MIT Press.

Lacy, S. (ed.) 1995 Mapping the Terrain: New Genre Public Art, Washington: Bay Press.

Landry, C. (2020) 'Arts, Culture and the City: An Overview', Built Environment, 46 (Arts and the City), 170181.

Li, X. \& Zhang, Y. (2020) 'Combining the Historico-Geographical and Configurational Approaches To Urban Morphology: The Historical Transformations of Ludlow, UK and Chinatown, Singapore', Urban Morphology 25(1), 23-41

Lovell, V. (2020) 'Artists and the Public Spaces of the City', Built Environment, 46 (Arts and the City), 214-228. Lynch, K. (1960) The Image of the City, London: The MIT Press.

Lynch, K. (1972) What Time Is this Place?, Cambridge: MIT Press.

McCarthy, J. (2006) 'Regeneration of cultural quarters: Public art for place image or place identity?', Journal of Urban Design, 11(2), 243-262.

Miles, M. (1997). Art, Space and the City: Public Art and Urban Futures, $\quad$ London; $\quad$ New York: Routledge.

Mitchell, W. (1990) 'The Violence of Public Art: Do the Right Thing', Critical Inquiry 16(4), pp. 880-899.

Monteiro. C., \& Pinho, P. (2021) 'Comparing Approaches in Urban Morphology', Journal of Urbanism: International Research on Placemaking and Urban Sustainability, DOI: 10.1080/17549175.2021.1936602

Negt, O. and Kluge, A. (1993) Public Sphere and Experience: Toward an Analysis of the Bourgeois and Proletarian Public Sphere, Minneapolis: University Minnesota Press.

Oliveira, V. \& Medeiros, V. (2015) 'Morpho: Combining Morphological Measures', Environment and Planning $B$ : Planning and Design 43(5), 805-825.

Oliveira, V., Monteiro, C., Partanen, J. (2015) 'A Comparative Study of Urban Form', Urban Morphology 19(1), 73-92.

Phillips, P. (1988) 'Out of Order: The Public Art Machine' Art Forum, 27(4), 92-97.

Porch, R. (2000) 'Public Art - An Off the Wall Proposition?', Urban Design (76), 16-20.

Rapoport, A. (1977) Human Aspects of Urban Form: Towards a Man-Environment Approach to Urban Form and Design, Oxford: Pergamon Press.

Remesar, A. (2005) 'Public Art. An Ethical Approach', In (Ed.) A. Remesar, Urban Regeneration A Challenge Cor Public Art, 7-13.

Rey, C. (2019) 'Graffiti and Architecture', Atlantis 29(2), 44-47.

Selwood, S. (1994) 'The Benefits of Public Art', Cultural Trends, 6(23), 37-55. 
Toy, E. and Görgülü, E. (2018) 'Kamusal Alanda Sanat Uygulamalarına Bir Örnek: Mural İstanbul', Journal of International Social Research, 11(56), 1150-1160.

Yaman, Z. Y. (2011) “Siyasi/Estetik Gösterge" Olarak Kamusal Alanda Anıt ve Heykel', METU JFA 28(1), 177190.

URL-1: https://kulturenvanteri.com/yer/ulus-ataturk-aniti-ankara/\#16/39.941761/32.854801

URL-2: https://www.turanakinci.com/eskiler/eski-taksim/page/5/

Page | 170

URL-4: http://www.azbilmisozneler.com/2016/10/timur-erkman-ankarada-komann-heykeli.html

URL-5:http://beyazgazete.com/fotogaleri/guncel-1/15-temmuz-sehitler-aniti-tum-fotograflar-26980/buyukfotograf-3/?pcount=6

URL-6: http://monroeistanbul.com/projects/icaf-2017.htm

URL-7: https://www.aa.com.tr/es/cultura/un-mural-de-escritores-conmemora-los-60-años-de-relacionesentre-colombia-y-turqu\%C3\%ADa/1592657

\section{Resume}

Cansu Demir Türközü graduated from METU Faculty of Architecture, Department of City and Regional Planning in 2012. She received her MSc degree from METU Master of Urban Design program in 2019. Her main research interests are urban morphology, spatial perception, environmental psychology, urban communities and cultural diversity. After three years of experience in the Chamber of City Planners, she currently works in business development for creative industries.

Olgu Çalışkan is an associate professor at METU Faculty of Architecture, Department of City and Regional Planning, and one of the instructors of the METU MUD (Master of Urban Design) Studio. His main research interests cover physical planning and design, urban morphology, urban design theory and methodology. His publications involve the guest editorial for the journal of Built Environment (2011), and several articles, including those in the Journal of Urban Design (2010), Journal of Architectural and Planning Research (2011), Urban Design International (2012, 2020), Urban Morphology (2017) and Journal of Planning Education and Research (forthcoming). He has been a jury member in a series of national and international design competitions. Within different design teams he has had award-winning projects within the recent national and international urban design competitions. 